\title{
Uncertainties towards a fossil-free system with high integration of wind energy in long- term planning
}

Pizarro-Alonso, Amalia; Ravn, Hans V.; Münster, Marie

Published in:

Applied Energy

Link to article, DOI:

10.1016/j.apenergy.2019.113528

Publication date:

2019

Document Version

Peer reviewed version

Link back to DTU Orbit

Citation (APA):

Pizarro-Alonso, A., Ravn, H. V., \& Münster, M. (2019). Uncertainties towards a fossil-free system with high integration of wind energy in long-term planning. Applied Energy, 253, [113528].

https://doi.org/10.1016/j.apenergy.2019.113528

\section{General rights}

Copyright and moral rights for the publications made accessible in the public portal are retained by the authors and/or other copyright owners and it is a condition of accessing publications that users recognise and abide by the legal requirements associated with these rights.

- Users may download and print one copy of any publication from the public portal for the purpose of private study or research.

- You may not further distribute the material or use it for any profit-making activity or commercial gain

- You may freely distribute the URL identifying the publication in the public portal 


\title{
Uncertainties towards a fossil-free system with high integration of wind energy in long-term planning
}

\author{
Amalia Pizarro-Alonso ${ }^{\mathrm{a}}$, Hans Ravn ${ }^{\mathrm{b}}$, Marie Münster ${ }^{\mathrm{a}}$ \\ ${ }^{a}$ Energy Systems Analysis, Technical University of Denmark (DTU), Produktionstorvet 426, 2800 \\ Kgs. Lyngby, Denmark \\ ${ }^{\text {b }}$ RAM-løse edb, Æblevangen 55, 2765 Smørum, Denmark
}

\begin{abstract}
There is a large amount of parametric uncertainties that might affect long-term energy planning, due to the inherent variability connected to the future. Most of these uncertainties are stochastic, i.e. they cannot be reduced, but can be better characterized. In an attempt to address this issue, studies often explore different alternative scenarios or perform local sensitivity analyses. While acknowledging their importance, it is evident that their traditional scope must be reconsidered, as those methods cannot consider interactions among parameters and hence might omit parameters that are highly influential. This study aims to explore the whole uncertainty range in order to identify the most critical parameters towards fossil-free energy systems with high integration of wind-based electricity. Denmark is used as a case study of a country with large wind resources, which are increasingly exploited. It pursues three steps: 1) Selection of parameters and characterization of their uncertainties, 2) Global sensitivity analyses through Morris sampling, and 3) Uncertainty propagation and Monte Carlo runs using Latin Hypercube sampling. Offshore wind upscaling will depend on technological improvements related to capital costs or efficiencies as well as on the system integration constraints. Hence, increasing deployments of offshore wind would require policies that foster technological learning, while promoting the cost-efficient integration of an increase in participation in the power mix, such as grid transmission expansion. Therefore, methods that deal with the whole uncertainty space should, to a larger extent, be implemented when uncertainties are assessed in association with long-term planning of systems with high integration of fluctuating renewable energy.
\end{abstract}

Keywords: energy systems modelling, fluctuating renewable energy, long-term planning, bottom-up optimization, uncertainty, global sensitivity analysis 


\section{Introduction}

The world is at a crossroads concerning the future of energy; climate change, increasing dependence on fossil fuels and volatile fuel prices are making our societies and economies vulnerable. In addition to energy issues, global demand for resources is increasing, driven by population growth and improving standards of living. These challenges call for a prompt action that must encourage a complete transformation of the existing energy system without jeopardizing security of supply.

The Intergovernmental Panel on Climate Change (IPCC) report on Global Warming of $1.5^{\circ} \mathrm{C}$ states that the share of primary energy from renewable (RE) sources (including biomass, hydro, solar, wind and geothermal, with direct equivalence method) will reach $38-88 \%$ in 2050 in all $1.5^{\circ} \mathrm{C}$ pathways (Rogelj, et al., 2018). More specifically, the IPCC $1.5^{\circ} \mathrm{C}$ report shows that the share of electricity supplied by renewables would rise to 59-97\%. Nevertheless, the share of the different RE technologies differs significantly between pathways, as the assumptions used in high renewable analyses with high shares of RE are being challenged. The IPCC $1.5^{\circ} \mathrm{C}$ report uses several Integrated Assessment Models (IAMs) which coupled energy-economy-land-climate systems from different regions. Apart from IAMs, energy systems models have been used for long-term strategic energy planning since the aftermath of the 1970s oil crisis. Currently, they are important tools for addressing the challenges that the world is facing, as they provide relevant insights on the supply and demand of energy, and represent the complex interactions of the energy sector (Pfenninger, Hawkes, \& Keirstead, 2014). In addition, energy systems models might ensure the techno-economic feasibility of specific energy pathways, especially in the power sector, which is difficult to capture in IAMs. Fluctuating renewable energy sources cannot be comprehensively represented in IAMs, as they deal with the world in an aggregated way, thus short-term dynamics are not integrated (Scholz, Gils, \& Pietzcker, 2017).

Energy models are used as a support tool during decision-making processes, as they show how the energy future might look like, such as electricity prices or $\mathrm{CO}_{2}$ emissions, depending on specific pathways for demographic and economic growth, behavioral changes, climate policies or technological improvements among others (Hall \& Buckley, 2016). There is a wide range of energy models with different underlying features, suitable for various purposes (Gargiulo \& Gallachoir, 2013). Energy systems models are often classified as bottom-up models, with a detailed technological representation; or as top-down models, with a more exact description of the total economy, and including the energy sector at an aggregated sectoral level (Bramstoft, Pizarro-Alonso, Karlsson, Kofoed-Wiuff, \& Münster, 2018). Energy system models can be simulation tools, based on an exogenous set of conditions; or optimization models, where decision variables are computed in order to meet the energy demand, while maximizing or minimizing an objective function, such as costs or welfare. This study uses a bottom-up optimization model, with a detailed technological representation of power, district heating and hydrogen systems.

Long-term energy systems analyses look into how the future might unfold. However, assertions cannot be attested or verifiable, as the future is a field of uncertainty (Jouvenel, 1967). A common criticism for optimization models is that the exactness of the numbers provided may infer a mirage of certainty, but results only display the part of "reality" given by the exogenous specifications (Fortes, Alvarenga, Seixas, \& Rodrigues, 2015). In addition, bottom-up models optimize energy supply, ceteris paribus to achieve the equilibrium. Nevertheless, the economic context modelled exogenously, such as fuel prices or agent behaviors, might become affected by the energy system in context with the full general equilibrium (Bohringer, 1998) (Hourcade, Jaccard, Bataille, \& Ghersi, 2006). 
Optimization models are often used with an international scope over a time span of 20-50 years, combining the short-term dispatch and its dynamics, and the longer horizon of investments. Models have a detailed representation of space and time, due to the growing requirements of RE integration. They include a substantial number of assumptions, simplifications, data aggregation and uncertainties, intrinsic to the irreducible-partial knowledge about the future. Therefore, the robustness of the conclusions must be tested in relation to the uncertainty of the parameters (Sterman, 2002) (Keppo \& Strubegger, 2010), as the results are intended to be used for supporting decisions taken by policymakers, such as formulation of energy plans (Nie et. al, 2018). Furthermore, they might impact significantly on strategic investment planning (Sun, Ellersdorfer, \& Swider, 2008) (Refsgaard, Sluijs, Brown, \& Keur, 2006), particularly in cases where decisions are irreversible (Nordhaus \& Yohe, 1983) or with a high degree of lock-in effect, such as long lifetimes and significant lead times of investments associated to the energy sector. Furthermore, because energy models aim to support the discussion concerning the required energy transition, it should be transparent how the results derived from certain assumptions (Wiese, Bökenkamp, Wingenbach, \& Hohmeyer, 2014). This will ensure a larger public acceptance of modelling results, and hence, a society demanding a change in the energy paradigm.

In an attempt to address uncertainty, studies conduct local sensitivity analyses in key parameters (Borgonovo \& Plischke, 2016), i.e. varying one factor at a time, which are not able to capture the impact of multiple uncertainties. In addition, most of the studies explore alternative scenarios in order to get some more robust information on what the energy system might look like, representing structured storylines of plausible futures (Pye, Sabio, \& Strachan, 2015) (Lunz, et al., 2016). Nevertheless, the number of scenarios is limited and only few uncertainties are captured (Fragkos, Kouvaritakis, \& Capros, 2015) (Trutnevyte \& Strachan, 2016). Examples of some techniques for structuring e and discussing energy scenarios are e.g. the scenarios-axes techniques or the story-andsimulation approach. The scenario-axes technique aims at identifying the two most important driving forces, i.e. those parameters that would be both uncertain and have a large impact on results (van't Klooster \& van Asselt, 2006). Analogously, the story-and-simulation approach uses logically constructed stories as simulations, showing the implications of different narratives that represent a wide range of future eventualities (Wilk, 1991). However, the identification of the driving forces or eventualities remains a challenge. It is often based on epistemological arguments, which might lead to the omission of relevant parameters, if scenario-developers are not aware of them or do not deem them as relevant.

Apart from local sensitivity analyses and explorative scenarios, uncertainties in energy system models are mostly dealt with through fuzzy mathematical programming, (dynamic) stochastic programming, robust optimization, and interval programming (Zeng, Cai, Huang, \& Dai, 2011) (Soroudi \& Amraee, 2013) (Ioannou, Angus, \& Brennan, 2017). Applications of stochastic modelling generally imply a very large computational time, which might be critical given the need to have models that are able to capture both short-term dynamics and long-term foresight. The number of variables grows exponentially with the amount of uncertainties evaluated, so that very often, only two or three uncertain parameters are considered (Bistline \& Weyant, 2013). Furthermore, there is often little information about the probability distribution functions of the uncertainty range of the parameters, which must be well defined for stochastic modelling (Usher, 2015). Fuzzy programming employs the fuzzy set theory to account for uncertainty when it results from vague information and ambiguity, and sets have non-sharp boundaries (Muela, Schweickardt, \& Garces, 2007) (Moradi, Hajinazari, Jamasb, $\&$ Paripour, 2013). When using interval programming, each uncertain parameter is represented as an interval number, which is useful when the probability distributions are unknown; however, some 
information might be missed, and it is impossible to consider situations that lie on the middle (Zhu, Huang, He, \& Zhang, 2012).

As energy systems models are to be used effectively and responsibly, supporting the decision-making process, the impact of uncertainties in the inputs to the model on the results must be well identified, quantified and addressed explicitly during the modelling and the interpretation of results, as shown by Mirakyan \& De Guio (2015).

This study suggests a combination of a global sensitivity analysis and uncertainty analysis in order to describe the impact of the whole parametric uncertainty space in the development of systems with high integration of wind-based energy. This is as opposite to most of the sensitivity analyses that explore the input space by moving along a one-dimensional corridor, but leave the multi-dimensional space unexplored (e.g. what happens if parameter P1 is higher than expected and parameter P2 is also higher? or P1 is higher and P2 is lower? or P1 is lower and P2 is higher?, etc.). Saltelli, et al. (2019) demonstrated that there is a systematic problem in practical sensitivity analyses developed in highly quoted papers concerning energy, and this study aims at proposing a framework for better exploring uncertainty in energy systems analyses.

There are several studies aiming at evaluating the impact of the whole parametric uncertainty space in the energy system, such as Fais, et. al (2016) and Pye, Sabio \& Strachan (2015) for a low-carbon United Kingdom with the TIMES model, Moret et al. (2017) with an energy systems model for Switzerland, Marcucci, et al. (2019) for the global energy system with the MERGE-ETL model or Bosetti, et al. (2015) with the global optimization model WITCH and MARKAL-US (for United States), and the global recursive dynamic simulation model GCAM (see section 5 for further information). Fais, et. al (2016); Pye, Sabio \& Strachan (2015); and Bosetti, et al. (2015) found that nuclear energy was playing the most crucial role in ensuring low-carbon developments. Nevertheless, societal preferences to nuclear technology are highly uncertain, as pointed out in the IPCC report of $1.5^{\circ} \mathrm{C}$ (Rogelj, et al., 2018). Moret et al. (2017) highlighted the importance of interest rates, and to a lower extent, of annual capacity factors in the future Swiss energy system cost when using a monthly resolution. Scenarios that deal with a larger share of solar and wind, with a detailed spatiotemporal representation, should be explored, as was also suggested by Becker, Rodriguez, Andresen, Schramm, \& Greiner (2015).

To the best of the authors' knowledge, there is no study especially dealing with the entire input uncertainty space in long-term planning of systems with high integration of wind energy. Global sensitivity analyses might enable the identification of the main sources of uncertainty to the deployment of the wind power industry at local, regional, or global levels. Creutzig, et al. (2017) pointed out that "some models, whose results were included in AR5 [IPCC Fifth Assessment Report, (IPCC, 2014)], imposed strict constraints on solar, such as requiring high levels of backup, limiting the total share of wind and solar [...], or limiting growth rates", which have been deemed as too conservative in subsequent assessments. Furthermore, Pietzcker, et al., (2017) found that improving power representation in IAMs substantially increased wind and solar optimal shares; therefore, a more detailled representation of variable renewable energy resources is needed. When using models with a more aggregated representation of space and time, which cannot capture short-term dispatch dynamics within the long-term planning horizon, the degree of deployment of variable renewable energy is significantly driven by that aggregation, and uncertainty cannot be properly characterized. This was e.g. observed when comparing the TIMES model (32 time slices and two power regions) with the detailed spatiotemporal model Balmorel (672 time slices and 13 power regions) for Denmark by Venturini, Pizarro-Alonso, \& Münster (2019), where the TIMES model did initially used extremely high investments in wind just for exporting to other countries that were modelled through a price 
interface, but without considering that the export price would decrease with the increase of exports. When the Mexican TIMES model (15 times slices and 5 power regions) was compared with the Balmorel model (288 time slices and 53 power regions), carried out by Solano-Rodríguez, PizarroAlonso, Vaillancourt, \& Martin-del-Campo (2018), the estimate of the TIMES model initially suggested that the result would be half the level of wind deployment compared to that of the Balmorel model due to the spatiotemporal induced constraints.

This paper aims to support the discussion around description of uncertainty characterization in energy systems with high integration of fluctuating renewable energy sources, especially wind. In this way this paper intends to support the identification of the main parameters affecting the deployment of the technology with a detailed representation of geography and time. Since the oil crisis of the 1970s, Denmark has been a pioneer in developing commercial wind power, and it was the first country in the world to construct an offshore wind farm. On June 2018, the Danish government signed an energy agreement with the support of all the sitting parties in their parliament. The aim of this agreement is that the North Sea will become a global leading region for offshore wind (Danish Ministry of Energy, Climate and Building, 2018). For all the above mentioned, uncertainties in a fossil-free Danish system are evaluated, as an example of a country with an already large share of variable renewable energy in its power mix: $40.7 \%$ of wind-based electricity generation in Denmark during 2018, slightly declining from the 2017 record of $43.4 \%$, but expecting to rise to $80 \%$ by 2035 . Therefore, results, although framed in a Danish setting, may be interpreted for application in other countries with large offshore wind potential and relatively low solar resources.

This study has been conducted with the bottom-up optimization model Balmorel with simultaneous least-cost optimization of investments and dispatch of power, district heating, and hydrogen (see section 2.1) (Ravn, 2001). This article presents a framework for dealing with many uncertain parameters when using the Balmorel model, without constituting a computational burden by performing many optimizations, but each one deterministic. The methodology includes a global sensitivity analysis with the elementary effects approach, also known as Morris sampling, followed by a statistical evaluation of the uncertainty propagation through Monte Carlo, using Latin hypercube sampling.

The aim of the study is twofold: 1) Provide robust solutions from energy system models to decisionmakers by proposing a framework for exploring the impacts of critical uncertainties to deliver fossilfree systems with a high integration of wind energy; and 2) Identify the parameters that most affect the uncertainty of energy prices and wind deployment, which could also represent the most efficient way to reduce them, e.g. through allocation of resources for research or through prioritizing specific policies.

In this manuscript, section 2 presents the suggested methodology, section 3 states the main heuristic assumptions and section 4 shows the results, which are further discussed in section 5. Concluding remarks are highlighted in section 6.

\section{Methodology}

This section introduces first the energy system optimization model Balmorel, as used in this study, including a description of the detail of spatial and temporal resolutions adopted. Afterwards, it presents the framework for uncertainty characterization in Balmorel applied in this analysis. 


\subsection{The energy systems model Balmorel}

Due to larger shares of variable renewable energy resources in future energy systems and the required integration of power, heating and transport sectors, the combination of long-term perspectives, considering the dynamics of short-term dispatch is needed. Authors have often represented the need for a combined approach, by initially optimizing long-term investment decisions, and subsequently, optimizing the short-term operations, defining capacities exogenously from the first step. Nevertheless, the impact of short-term variabilities might influence investment decisions, and with growing shares of variable renewable energy it should not be neglected. This imposes computational challenges, given by the need to have energy system models with detailed representation of space and time.

The model Balmorel has been used for a broad range of energy systems analysis (Wiese, et al., 2018), specially dealing with the integration of large shares of variable renewable energy (Karlsson \& Meibom, 2008), as it considers the electricity and district heating sectors in an international perspective with flexible spatial and temporal resolutions (Pizarro-Alonso, Cimpan, Söderman, Ravn, \& Münster, 2018). Initially, Balmorel was mostly used on a North-European context; nevertheless, it has also been applied in a wide international context, e.g. for developing an electricity system Master plan for the Eastern Africa Power Pool (EA Energy Analyses; Energinet, 2014), to develop power scenarios for the Chinese energy transition (Xiong, Zhang, Mischke, \& Zhang, 2014), or to assess mitigation instruments in the power sector in Mexico (Barragán-Beaud, Pizarro-Alonso, Xylia, Syri, \& Silveira, 2018). Therefore, due to the large use of the Balmorel model for analyzing a growing penetration of variable renewable energy sources, it has been chosen in this study to assess the impact of uncertainties in long-term planning models that entail a detailed representation of technical components of the energy system.

Balmorel is an open-source model written in the GAMS (General Algebraic Modelling System) language. It is a partial equilibrium model with a bottom-up approach, and in this study simulates and optimizes generation, transmission and consumption of electricity, district heating and hydrogen (Pizarro-Alonso, Cimpan, Söderman, Ravn, \& Münster, 2018), as depicted in Figure 1. The exogenous variables used in the model are fuel prices, resource availability, selected final energy demands, committed and planned power and district heating plants (heavily influenced by policies, e.g. nuclear or coal thermal plants capacity depending on phase-out policies) and available transmission capacity. Other variables related to electricity production and transmission, district heating production and storage, as well as hydrogen production and storage, are subject to free optimization across all the geographic entities and time slices in the model. Balmorel is deterministic and assumes perfectly competitive markets.

In this study, the analysis is based on minimizing total socioeconomic costs for satisfying the energy demand over the whole area modelled in an hourly time resolution over one full year (objective function). The optimization is done at each selected year, e.g. 2050 in this study, through a myopic approach, without any knowledge about what happens beyond that specific time (Hedenus, Johansson, \& Lindgren, 2013) (Keppo \& Strubegger, 2010) (Babrowski, Heffels, Jochem, \& Fichtner, 2014). The foresight is perfect within the year, assuming that the model can fully anticipate the future in the short-term planning horizon of that year; e.g. electricity and district heating (DH) demand in a specific location at a given time, and fluctuation of power generation from wind. 


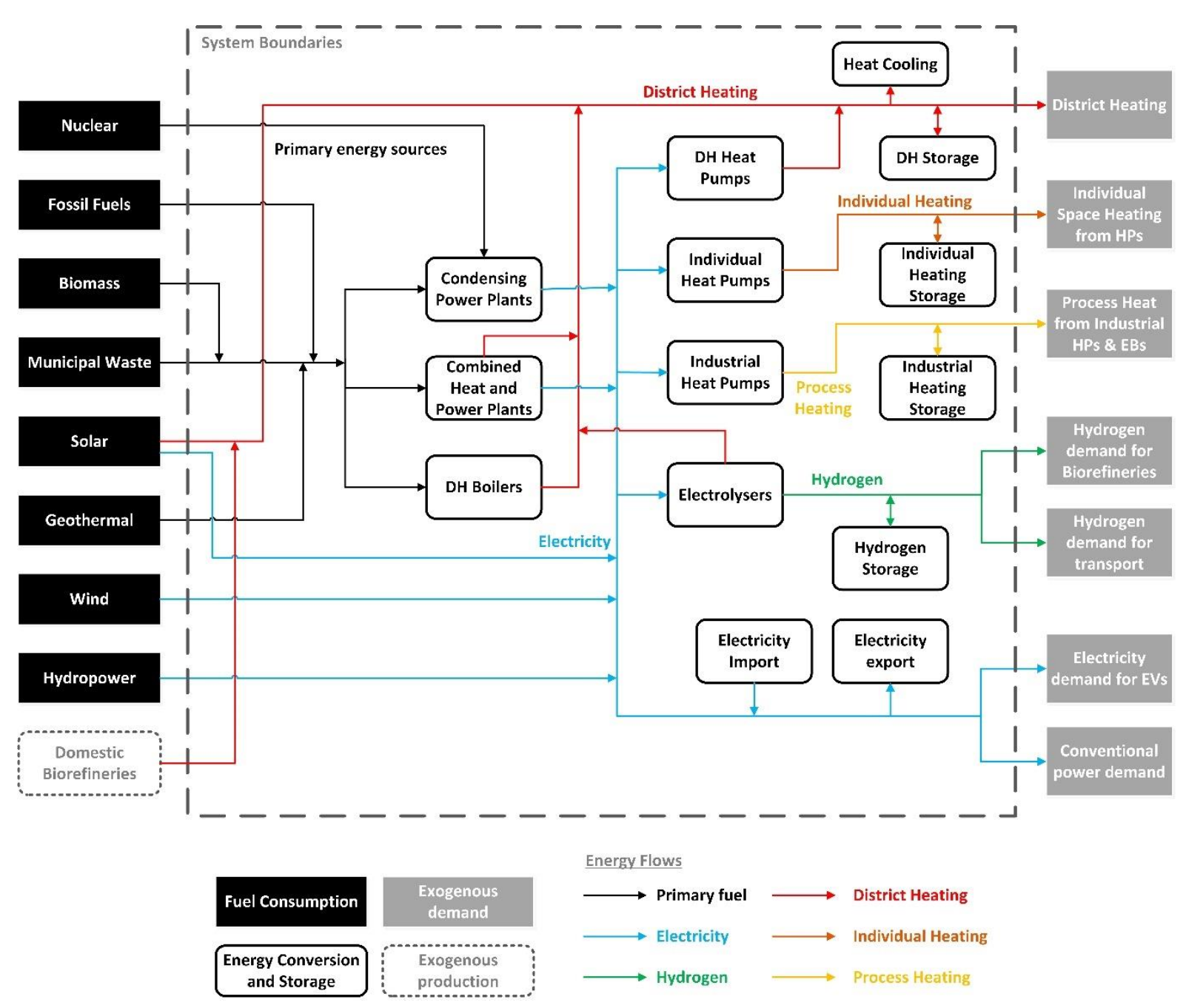

Figure 1. The Balmorel energy system model (as applied in this study).

\subsubsection{Spatial and temporal resolutions}

The Danish electricity market is part of an increasingly connected power grid, the electricity price is cleared on the Nordic and German markets. Therefore, an international approach is taken, where the power sector of Germany, Norway, Sweden and Finland is also modelled; nevertheless, these five countries are considered as isolated from the remaining parts of Europe (see Figure 2).

Due to the interplay between the electricity and district heating sectors (e.g. cogeneration plants and heat pumps), and of these sectors with hydrogen production through electrolysis, an integrated modelling approach is also required. Hydrogen and district heating demand is modelled for the five countries. Furthermore, a detailed spatial representation of Danish district heating networks is used: the 34 largest DH grids are modelled independently, as unique, and the rest of networks are aggregated by power regions, i.e. Denmark East and West, as shown in Figure 3. 


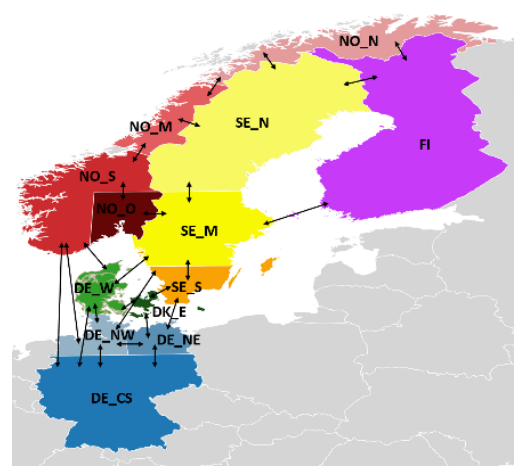

Figure 2. Power transmission regions in Balmorel (as applied in this study).

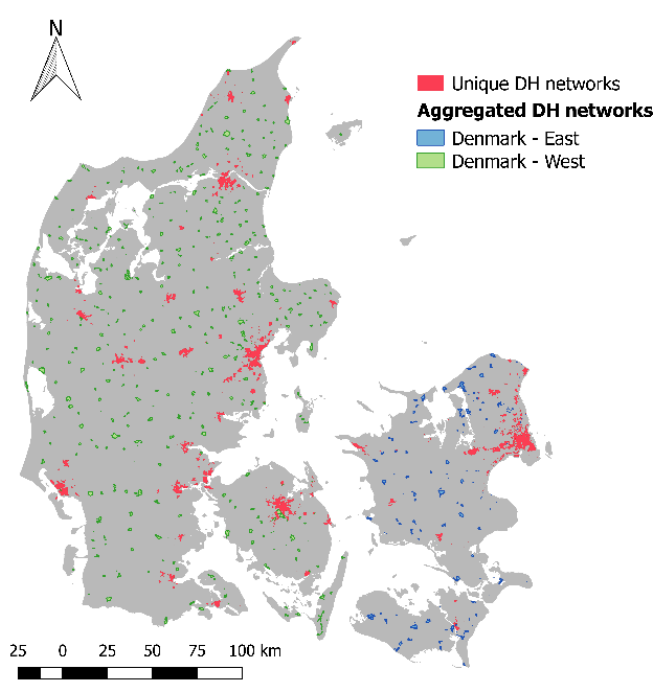

Figure 3. Representation of Danish district heating networks in the Balmorel model in this study (Bornholm Island is also represented in the model but not included in this map).

This study uses an hourly time resolution to be able to capture sudden changes from intermittent generation (e.g. wind, solar) that might affect the net total residual demand, It excludes intra-minute or inter-minute variations, which are considered to be handled in the reserve market, and are therefore, outside our scope. Nevertheless, modelling 8760 time slices, i.e. hours, for each geographical entity would imply a very large number of equations and endogenous variables, creating a computational burden. Therefore, in this study, four full weeks with an hourly resolution are selected to represent both daily and seasonal patterns in energy demand and fluctuating renewable production. The selection of the four full weeks seeks to minimize the differences between the annual duration curve made of 8760 hourly time slices, and the aggregated one, built with 672 (4 weeks $\mathrm{x}$ 168 hours) time slices, while covering the four seasons. Afterwards, these four full selected weeks with an hourly resolution are scaled with the annual values to ensure that balances are satisfied. As illustrated in Figure 4, the aggregated load duration curves for electricity demand and wind power production are very similar to the annual ones, including the representation of the right-hand and lefthand extreme sides for offshore wind production, although smoothening the peak on the left-hand side of the electricity demand. The selection of the four representative weeks minimizes the differences in the residual demands compared to the annual values, aiming at reducing the structural uncertainty of the model introduced by temporal aggregation. 

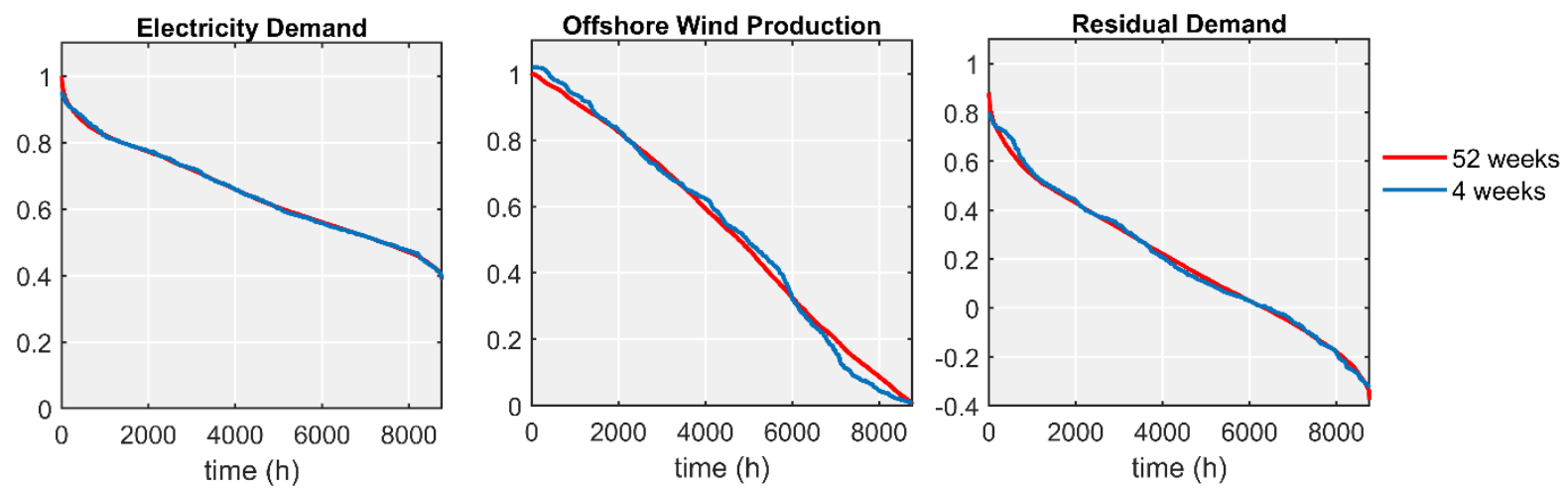

Figure 4. Duration curves for 52 full weeks vs. 4 representative weeks (hourly resolution) in West Denmark. The residual demand is estimated assuming the electricity demand minus $70 \%$ of wind production.

\subsection{Methodology for characterization of the uncertainty in Balmorel}

There are two main types of uncertainty in the energy system model Balmorel:

- Structural uncertainty. Any model is an abstraction, approximation and interpretation of the reality; which allows us to deal with the world in a simplified manner (Rothenberg, 1989). The mismatch between the real system and the assumed one, due to the specific mathematical formulation or the model structure, results in uncertainty in the results (Refsgaard, Sluijs, Brown, \& Keur, 2006).

- Parametric uncertainty. Uncertainty about the exogenous variables, i.e. input parameters.

Consistency of the model can be made by comparing with the results from other models that share the same underlying assumptions (Yue, et al., 2018), e.g. assessing equifinality. In this study, the Balmorel model is used for long-term forecasts, which have been corroborated against historical data in prior analysis (Tveten, 2015), and compared to other model results, such as TIMES-DK (Venturini, Pizarro, \& Münster, 2019). In this manuscript, we have purposely avoided the term "model validation", as suggested by Saltelli, et al. (2008), since Balmorel outputs cannot be proven true. Explicit characterization of the structural uncertainty is out of the scope of this manuscript, as this study focuses on analyzing the impact of parametric uncertainty on the optimization results, which might encompass the inherent uncertainty associated to nature, societal variabilities (e.g. policies), technological surprises, new developments or breakthroughs in technology (van Asselt \& Rotmans, 2002), etc. Furthermore, as Balmorel is a partial equilibrium model, uncertainties associated to the exogenous assumptions of the economic system and the impact of the energy sector in the general equilibrium, such as demands or fuel prices, are also analyzed.

Sensitivity analysis is "the study of how uncertainty in the output of a model can be apportioned to different sources of uncertainty in the model input" (Saltelli, Tarantola, Campolongo, \& Ratto, 2004). An uncertainty analysis quantifies the uncertainty in the modeling output, and ideally sensitivity and uncertainty analyses should be run in tandem (Saltelli, et al., 2008). Therefore, sensitivity analysis assists in the estimation of the most contributing parameter variations in the results as well as those inputs that are non-influential, providing an indication of the importance of specific parameters. The first approach for handling uncertainty were local sensitivity analyses that evaluated the impact of an input change in selected outputs while fixing the others, and which are traditionally used in energy systems analyses. From the late 1980s, to overcome the limitations of one-at-a-time perturbations, methodologies for global sensitivity analyses were developed, which can consider the whole variation range of several parameters (Saltelli, et al., 2008). Due to the large number of stochastic uncertainties associated to energy systems models and the relatively high computational time associated to 
Balmorel modeling resulting from the detailed spatial and temporal representation, the screening method of Morris sampling is applied (see section 2.2.1). Morris sampling allows characterizing uncertainty semi-quantitatively, i.e. identifying and ranking influential parameters, but not quantitatively, as done e.g. in variance-based quantitative methods, such as Sobol indices, but which are computationally demanding (Kristensen \& Petersen, 2016). Hence, an uncertainty analysis is subsequently required to quantify the effects of parametric uncertainties on the overall modeling results but considering only those parameters that had an influence. The work follows the stages depicted in Figure 5 and introduced below, which are further described in the next subsections:

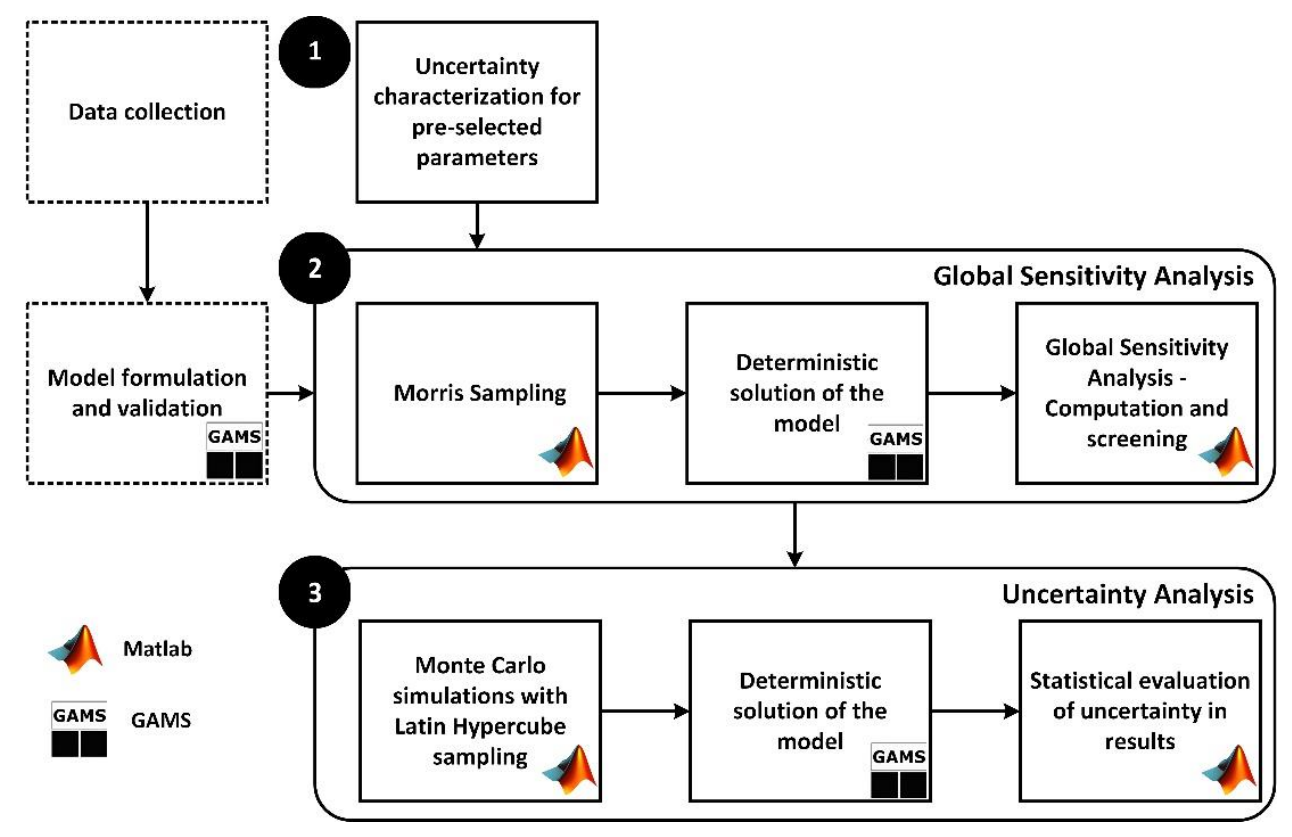

Figure 5. Methodology for analyzing uncertainty in Balmorel applied in this study.

1. Heuristic selection of parameters that might affect the selected modeling results the most (Danish electricity and district heating prices, and deployment of wind in Denmark - see section 3.3.1), and characterization of their uncertainty. Due to the large number of parameters in energy systems models, only some of them are initially selected, based on literature search and expert review (see section 3). Filtering is critical, in order to ensure the computational tractability of the global sensitivity analysis. Nevertheless, the choice of parameters must be done in a thorough way, and it was initiated by a literature review based on historical analyses and accompanied by a small expert participative process.

2. Global Sensitivity Analysis. Morris sampling is applied for assessing the relative impact of input parametric uncertainties on the selected modeling outputs. This is used to identify and rank the most critical parameters, and to simplify the model for subsequent steps, by fixing non-influential parameters. Furthermore, the prioritization of influential parameters could support the establishment of actions, such as stringent policies, research focus or data acquisition improvement requirements, which could minimize the uncertainty of the outcome.

3. Uncertainty Analysis. Monte Carlo simulation with Latin Hypercube sampling (LHS) is applied for quantifying uncertainty in the results based on the uncertainty in the inputs that had an influence on the previous step.

In the following subsections, steps 2 and 3 are further described for analyzing the uncertainty in longterm energy planning when using the optimization model Balmorel. 


\subsubsection{Global sensitivity analysis: Morris Sampling}

Global sensitivity analyses explore the whole uncertainty range of the inputs, revealing which of these contribute the most to the variance in selected model outputs, or ascertaining some interaction effects within the model (Branger, Giraudeta, Guivarcha, \& Quirion, 2015). The advantage of the screening method of Morris sampling is that it discretizes the input space for each parameter, and then performs local sensitivity analyses in a global context, being computationally less demanding.

The method uses a special sampling technique, Morris sampling (Morris, 1991), which seeks to explore the uncertainty input space with a minimum number of points. Morris sampling has two degrees of freedom to be specified: $p$, the number of value levels that an uncertain input parameter can take within its uncertainty range in the unit hypercube [0,1], which should be an even number to be optimal, such as 2, 6 or 8; and $r$, the number of repetitions, typically between 10 and 50 (Campolongo, Cariboni, \& Saltelli, 2007).

The design is based on generating a random starting point for each trajectory $r, \theta^{\mathrm{r}}$, and then completing it by moving one factor at a time with a $\Delta$ increase or decrease, with equal probability but always ensuring that it lies within the uncertainty range. $\Delta$ is a perturbation factor of $\theta_{i}$, applied in a random order of $i$ (Campolongo, Cariboni, \& Saltelli, 2007), calculated with Equation 1, and which guarantees that the $p$ levels have equal probability of being chosen (see Figure 5). Samples are assumed to be uniformly distributed in $[0,1]$, and then transformed from the $i$-dimensional hypercube to their uncertainty distributions.

$$
\Delta=\frac{p}{2 \cdot(p-1)}
$$

Figure 5 exemplifies Morris sampling, where a base value (circles with a black line mark) is randomly selected for each repetition, and all the trajectory points are generated by randomly increasing or decreasing by $\Delta$ within the uncertainty range, one-at-a-time, each of the $i$-th input parameters. The number of trajectories is equivalent to the defined number of repetitions.

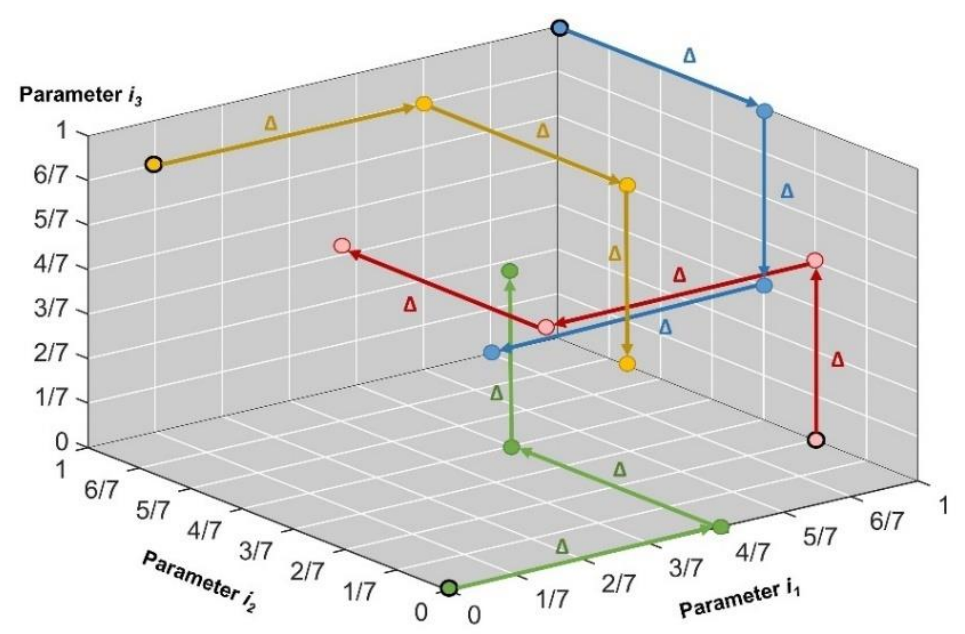

Figure 6. Morris sampling example - representation of the eight-level grid $(p=8, \Delta=4 / 7)$ in the three-dimensional unit hypercube input space [0,1] for four repetitions (trajectories), and 16 runs, represented by dots-sampling points.

The method estimates the elementary effects, $E E$, on the results from variation of each input parameter $i, \theta_{i}$, at each repetition, i.e. a local sensitivity analysis. The elementary effect for each input $i$ on each output $y$ for the $r$-th repetition, is calculated as the partial derivative of $y$ with respect to $i$, as shown in Equation 2; where $y(\theta)$ is the scalar model output evaluated at input parameters 
$\left(\theta_{1}, \theta_{2}, \theta_{i}, \ldots, \theta_{M}\right)$, whereas $y\left(\theta_{1}, \theta_{2}, \theta_{i}+\Delta, \ldots, \theta_{M}\right)$ is the scalar model output corresponding to a $\Delta$ change in $\theta_{i}$.

$$
E E_{i}^{r}=\frac{y\left(\theta_{1}^{r}, \theta_{2}^{r}, \theta_{i}^{r}+\Delta, \ldots, \theta_{M}^{r}\right)-y\left(\theta^{r}\right)}{\Delta} \text { for } i=1: M
$$

The total number of runs needed to calculate the $E E$ for $M$ parameters, repeated $r$ times, is $r(M+1)$, which is equivalent to the total number of local sensitivity analyses performed. Once all $E E_{i}$ have been calculated for $r$ random samples of input parameters, sigma-scaling of $E E_{i}$ is applied, using Equation 3, so that the impacts of input parameters on various outputs can be comparable. $\sigma_{i}$ is the standard deviation of the input parameters, while $\sigma_{y}$ is the standard deviation of the output $y$ from optimization results.

$$
S E E_{i}^{r}=E E_{i}^{r} \cdot \frac{\sigma_{i}}{\sigma_{y}} \quad \text { for } \quad i=1: M
$$

The statistical summary of the sigma-scale elementary effects associated to the $i$-th parameters from all the trajectories $r, S E E_{i}^{r}$, is calculated: the arithmetic means, $\mu_{i}^{S E E}$, and the standard deviations, $\sigma_{i}^{S E E}$, which are assembled in scatter plots for visualization. The mean, $\mu_{i}^{S E E}$, assesses the overall influence of the parameter $i$ on the output $y$, and the standard deviation, $\sigma_{i}^{S E E}$, estimates interactions effects with other factors, where a high value indicates that the elementary effects would be strongly affected by the choice of the other parameters' values (Campolongo, Cariboni, \& Saltelli, 2007). Furthermore, in each plot, two lines corresponding to the positive and negative double estimated standard error of the mean, $\operatorname{sem}_{i}$, against $\sigma_{i}$, are drawn (see the application of the methodology in Figure 11):

$$
\operatorname{sem}_{i}=\frac{2 \cdot \sigma_{i}}{\sqrt{r}} \text { for } i=1: M
$$

As described by Sin, Gernaey, \& Lantz (2009), if the elementary effect of a parameter $\left(\mu_{i}^{S E E}, \sigma_{i}^{S E E}\right)$ falls within the two lines $\left( \pm \operatorname{sem}_{i}, \sigma_{i}\right)$, its impact can be interpreted as negligible on the model output variation.

\subsubsection{Uncertainty analysis: Monte Carlo simulation}

Following the Morris screening, the Monte Carlo simulation procedure presented by Sin, Gernaey, \& Lantz (2009) is applied for estimating the uncertainty of the results of interest. Several other uncertainty analysis methods are available; however, the Monte Carlo procedure is generally accepted as computationally-effective and reliable (Helton \& Davis, 2003). One of the main drawbacks of using Monte Carlo simulation is that a large number of samples might be necessary to obtain a reasonable accuracy, which implies long computational times. Therefore, only those factors that have a significant impact on the results in the Morris screening are considered for Monte Carlo simulations, and the non-influential parameters are fixed in their reference value.

Monte Carlo simulation is a method for evaluating a deterministic model using sets of random numbers, within the uncertainty range characterized in step 1 (see Figure 5), as input parameters. It does not require any modification of the original Balmorel model. The uncertainty analysis procedure applied involves the following three steps, as also briefly depicted in Figure 5:

1. Probabilistic sampling from input uncertainty. In order to obtain random numbers but ensuring a certain degree of stratification over the range of each of the $M$ input parameters, the Latin Hypercube Sampling method is applied (Helton \& Davis, 2003). The $N$ near-random defined samples, $\theta_{j}$, contains one value for each input parameter, $\theta_{i, j}$ : 


$$
\theta_{j}=\left[\theta_{i, j}\right] \text { for } i=1: M \text { and } j=1: N
$$

Stratification makes likely that the estimate is better than with a complete random sample of the same size, i.e. $N$, improving the computational efficiency as less runs would be required (Soroudi \& Amraee, 2013) (Helton, Johnson, Sallaberry, \& Storlie, 2006). In the Latin Hypercube Sampling, exemplified in Figure 7, the cumulative distribution function, i.e. [0,1], of each parameter is divided into $N$ equally probable strata. One value from each stratum is randomly selected. The $N$ values obtained for each parameter are randomly combined, forming an $N^{*} M$ tuple. There is no even distribution of points across the uncertainty space, as it would happen with optimal space-filling sampling, thus ensuring certain degree of randomness within the equiprobable strata.

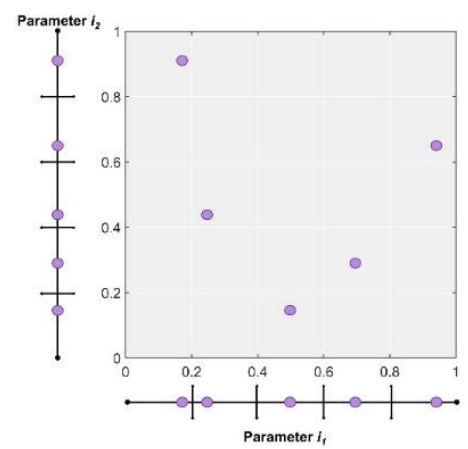

Figure 7. Example of two-dimensional Latin Hypercube sampling $[0,1]$ with $N=5$. Dots represent the sampling points.

2. Propagation of the input uncertainty, $\theta_{N \times M}$, to the Balmorel model input data and solving the model with each of the $N$ samples. Thereby, producing one solution for each row vector $\theta_{j}$, i.e. a set of $N$ values of the selected model outputs $y, Y_{j}$.

3. Statistical evaluation of the model results to characterize their uncertainty with respect to the uncertainty in the input parameters, e.g. cumulative distribution functions shown in Figure 14.

The following section describes the main data associated to the methodological framework that has been presented.

\section{Scenario description}

Denmark aims to be climate-neutral and independent of fossil fuels by 2050 (Danish Ministry of Energy, Utilities and Climate, 2018). The government has a few energy policy milestones on the journey towards decarbonization, such as $40 \%$ reduction of greenhouse gas (GHG) emissions by 2020 compared to 1990 levels, phase out of oil burners and coal power plants by 2030, and net fossil-free electricity and heating sectors by 2035 . The scope of this article is to analyze how Denmark could achieve those targets for the electricity, district heating and hydrogen systems in the year 2050, in the most cost-effective way, while identifying the main sources of uncertainty and thus, constraints and drivers towards a low-carbon development.

\subsection{Definition of the Reference scenario}

The Reference scenario in this study represents an image of how the future might unfold, given a future set of plausible assumptions that would allow countries to fulfill their climate pledges, although the specific regulation might still not be in place to achieve it. The Reference scenario is not a forecast, since there are many unknowns whose influence in the results are subsequently analyzed. 
Based on studies from the Danish Energy Agency that analyzes different coherent pathways of the future energy supply, a scenario representing net fossil-free electricity and district heating sectors, and a massive electrification within transport and industry, is considered (Danish Energy Agency, 2014). This situation has also been deemed as the preferred pathway from a socio-economic perspective under climate constraints in other Danish energy systems analysis (Venturini, Pizarro, \& Münster, 2019). Furthermore, hydrogen is used for biogas upgrading to biomethane in order to limit biomass use, because of the fact that the sustainability of imported biomass might be arguable (Pizarro Alonso, Cimpan, \& Münster, 2018), and to minimize imports and increase subsequently the degree of energy self-sufficiency. Data can be found in Balyk, et al. (2019), and values related to time-series and power transmission in Pizarro-Alonso, Cimpan, Söderman, Ravn, \& Münster (2018). It is assumed that the country must be self-sufficient in terms of annual power generation and could only become a net exporter of electricity.

The underlying framework for Sweden, Norway and Finland is a Nordic Carbon Neutral Scenario $(C N S)$ (Norden; IEA, 2016), which "reflects the national climate targets in the Nordic countries for 2050, where Nordic $\mathrm{CO}_{2}$ emissions fall by $85 \%$ compared to 1990 levels" (IEA, 2013). The CNS would still require offsets to be used in order to ensure the goal of net zero emissions, aimed by the Nordic countries in their Declaration on Nordic Carbon Neutrality, signed on January 2019 as their response to the findings of the IPCC $1.5^{\circ} \mathrm{C}$ report. For Germany, a two-degree scenario (2DS) is assumed, reflecting the German contribution, to achieve "an energy system consistent with an emissions trajectory that recent climate science research indicates would give an $80 \%$ chance of limiting average global temperature increase to two degrees Celsius". The German scenario includes the nuclear and coal phase-out plans by 2022 and 2038, respectively.

\subsection{Selection of parameters and characterization of their uncertainty}

The input parameters, whose uncertainty is considered in this analysis, are related to weather induced variations, fuel prices, local resource potentials, technology development (improvement), evolution of the nuclear capacity, power transmission lines, economic growth and energy demand. The selection of these parameters has been done through discussion among authors of this manuscript as well as colleagues; nevertheless, the creation of a larger experts working group to better identify the most critical data would be recommended. The characterization of the uncertainty range of the selected parameters can be found in the Supplementary Material 1 and is summarized in Table 1. Uniform distribution functions have been assumed, due to the lack of data regarding probability distributions, excepting for weather-induced variations. Furthermore, preliminary research preceding this study showed no significant changes when using normal distributions for meteorological variations. Therefore, uniform distribution functions have been used for simplicity, although a better characterization of the uncertainty in further research is recommended.

There are two types of parametric uncertainty: epistemic, due to limited information and a lack of knowledge about the appropriate data, and stochastic, due to variation of aleatory nature. The uncertainty ranges in Table 1 correspond mostly to the stochastic variability one sees in the system being modeled, as the future remains unknown and could potentially evolve in many ways. Therefore, perfect knowledge cannot provide a deterministic solution; however, it will provide a "perfect" characterization of the variability (Refsgaard, Sluijs, Højberg, \& Vanrolleghem, 2007). 
Table 1. Parameters uncertainty assuming uniform distribution by 2050 ( $R=$ value in the Reference scenario)

\begin{tabular}{|c|c|c|c|}
\hline Parameter & Description & Lower bound & Upper bound \\
\hline$\pi$ On Wind & Capacity factor of Danish onshore wind & $-20 \% \cdot \mathrm{R}$ & $+20 \% \cdot \mathrm{R}$ \\
\hline$\pi$ Off Wind & Capacity factor of Danish offshore wind & $-20 \% \cdot \mathrm{R}$ & $+20 \% \cdot \mathrm{R}$ \\
\hline$\pi_{\text {Solar PV }}$ & Capacity factor of Danish solar photovoltaic panels & $-10 \% \cdot \mathrm{R}$ & $+10 \% \cdot \mathrm{R}$ \\
\hline$\pi$ Solar DH & Capacity factor of Danish solar collectors & $-10 \% \cdot \mathrm{R}$ & $+10 \% \cdot \mathrm{R}$ \\
\hline$\pi_{\text {Hydropower }}$ & Hydropower production in Norway and Sweden & $-20 \% \cdot \mathrm{R}$ & $+20 \% \cdot \mathrm{R}$ \\
\hline PWP price & Wood pellets price & $-40 \% \cdot \mathrm{R}$ & $+40 \% \cdot \mathrm{R}$ \\
\hline$\mu_{\text {Straw }}$ & Straw allocated for electricity and district heating in Denmark & $0.0 \mathrm{PJ}$ & $54.0 \mathrm{PJ}$ \\
\hline$\mu_{\text {Biogas }}$ & Biogas allocated for electricity and district heating in Denmark & $42.0 \mathrm{PJ}$ & $64.7 \mathrm{PJ}$ \\
\hline$\mu_{\text {MSW }}$ & Municipal solid waste for incineration in Denmark & $0.0 \mathrm{PJ}$ & $45.9 \mathrm{PJ}$ \\
\hline KOn Wind & CAPEX onshore wind turbines & $-20 \% \cdot \mathrm{R}$ & $+20 \% \cdot \mathrm{R}$ \\
\hline KOff Wind & CAPEX offshore wind turbines & $-20 \% \cdot \mathrm{R}$ & $+20 \% \cdot \mathrm{R}$ \\
\hline KSolar PV & CAPEX solar photovoltaic panels & $-20 \% \cdot \mathrm{R}$ & $+20 \% \cdot \mathrm{R}$ \\
\hline KSolar DH & CAPEX solar collectors & $-20 \% \cdot \mathrm{R}$ & $+20 \% \cdot \mathrm{R}$ \\
\hline КВio CHP & CAPEX biomass cogeneration plant & $-35 \% \cdot \mathrm{R}$ & $+35 \% \cdot \mathrm{R}$ \\
\hline KGasTurbine & CAPEX gas turbine cogeneration plant & $-20 \% \cdot \mathrm{R}$ & $+20 \% \cdot \mathrm{R}$ \\
\hline KGasEngine & CAPEX gas engine & $-20 \% \cdot \mathrm{R}$ & $+20 \% \cdot \mathrm{R}$ \\
\hline KGasBoiler & CAPEX gas boiler & $-20 \% \cdot \mathrm{R}$ & $+20 \% \cdot \mathrm{R}$ \\
\hline КHeatPump & CAPEX heat pumps & $0.5 \mathrm{M}_{2015} / \mathrm{MW}_{\mathrm{h}}$ & $1 \mathrm{M}_{2015} / \mathrm{MW}_{\mathrm{h}}$ \\
\hline KHeatStor-L & CAPEX inter-seasonal heat storage & $-50 \% \cdot \mathrm{R}$ & $+50 \% \cdot \mathrm{R}$ \\
\hline К & CAPEX alkaline electrolyzer & $-35 \% \cdot \mathrm{R}$ & $+35 \% \cdot \mathrm{R}$ \\
\hline КH2Stor-C & CAPEX hydrogen storage & $-30 \% \cdot \mathrm{R}$ & $+30 \% \cdot \mathrm{R}$ \\
\hline vAEC & Efficiency of alkaline electrolyzer & $-5 \% \cdot \mathrm{R}$ & $+5 \% \cdot \mathrm{R}$ \\
\hline VHeatPump & Efficiency of Heat Pumps & $-15 \% \cdot \mathrm{R}$ & $+100 \% \cdot \mathrm{R}$ \\
\hline$\lambda_{\text {nuclearSE }}$ & Nuclear capacity in Sweden & $0 \mathrm{MW}$ & $5677 \mathrm{MW}$ \\
\hline$\lambda_{\text {nuclearFI }}$ & Nuclear capacity in Finland & $0 \mathrm{MW}$ & $3680 \mathrm{MW}$ \\
\hline$\tau_{\text {availability }}$ & Availability of Danish power transmission lines & $50 \%$ & $95 \%$ \\
\hline$\tau_{\text {Inv Lim }}$ & Investments limits in new transmission capacity & 0 & $+100 \% \cdot \mathrm{R}$ \\
\hline$\tau_{\text {Inv Cost }}$ & CAPEX in transmission lines connecting Denmark & $-30 \% \cdot \mathrm{R}$ & $+30 \% \cdot \mathrm{R}$ \\
\hline DR & Discount rate & $3 \%$ & $5 \%$ \\
\hline$\delta_{\text {Elec DK }}$ & Electricity demand in Denmark & $-25 \% \cdot \mathrm{R}$ & $+25 \% \cdot \mathrm{R}$ \\
\hline$\delta$ Elec DK-EV & Electricity demand in Denmark for Electric Vehicles & $-25 \% \cdot \mathrm{R}$ & $+25 \% \cdot \mathrm{R}$ \\
\hline$\delta$ Elec DE & Electricity demand in Germany & $-25 \% \cdot \mathrm{R}$ & $+25 \% \cdot \mathrm{R}$ \\
\hline$\delta_{\text {Elec NO }}$ & Electricity demand in Norway & $-25 \% \cdot \mathrm{R}$ & $+25 \% \cdot \mathrm{R}$ \\
\hline $\boldsymbol{\delta}_{\text {Elec SE }}$ & Electricity demand in Sweden & $-25 \% \cdot \mathrm{R}$ & $+25 \% \cdot \mathrm{R}$ \\
\hline ठElec FI & Electricity demand in Finland & $-25 \% \cdot \mathrm{R}$ & $+25 \% \cdot \mathrm{R}$ \\
\hline$\delta_{\text {DH DK }}$ & District heating demand in Denmark & $-15 \% \cdot \mathrm{R}$ & $+15 \% \cdot \mathrm{R}$ \\
\hline
\end{tabular}

It should be noted that it was beyond the scope of this analysis to make a very detailed characterization of parametric uncertainty, but rather a framework that could deal with it in an appropriate and simple manner. Some of this uncertainty characterization factors come from a Delphi process conducted by the Danish Energy Agency during the development of their "Technology Catalogue for Energy Plants", and we have adopted their outcomes regarding uncertainty. Further research should promote an open discussion towards those uncertainties, which could allow characterizing them better.

\subsection{Global sensitivity analysis and uncertainty analysis}

In this study, the Morris sampling was designed to calculate $r=35$ elementary effects for the 36 parameters, resulting in 1295 simulations, which corresponds to $35 \cdot(36+1)$. It was conducted with $p=8$, which correlates to the $12.5^{\text {th }}$ percentile of the parameters' uniform distribution $[0,1]$ (Campolongo, Cariboni, \& Saltelli, 2007). 
Monte Carlo simulations were conducted for the non-negligible parameters from the Morris screenings. A confidence interval of $99 \%$ was chosen to perform the statistical analysis of the results. Different sizes of samples, i.e. number of data points, were generated using Latin Hypercube Sampling, with the goal of analyzing the impact of the sample size in the characterization of the results uncertainty.

This study assumes that parameters are independent of each other, i.e. there is no correlation between them, and each one is independently sampled, in order to decrease the complexity. Nevertheless, the sampling techniques used, Monte Carlo and LHS, have a stratified structure that covers a very wide range of the uncertainty space, most probably including the effect of possible correlations. Therefore, although some parameters might be correlated, such as weather induce variations in wind, solar irradiation, and precipitation patterns, their correlated impact is most likely considered in some of the model repetitions, although their results might not be representative enough.

\subsubsection{Selection of modeling output analyzed}

As investments in the energy sector depend on expectations for developments in the wholesale market prices, the effect of parametric uncertainty on the annual average electricity and district heating prices in Denmark is assessed. The optimization from Balmorel seeks to minimize total socioeconomic costs for satisfying the electricity, district heating and hydrogen demands for a given year. Electricity and district heating prices are dual variables that represent long-term marginal costs of producing one unit more of electricity or heat. Furthermore, as this study has a focus on the wind industry, the parametric uncertainty is also evaluated with respect to the level of wind capacity deployment in Denmark.

\section{Results}

\subsection{Results of the Reference scenario}

The size of a model influences its solving time and the Reference scenario model of this study can be characterized by $3,087,823$ rows, i.e. equations, and 3,289,007 columns, i.e. variables or endogenous parameters that are optimization results. CPLEX solves the linear programming model using the barrier algorithm in approximately 850 seconds in a computer with a $2.19 \mathrm{GHz}$ processor and $32 \mathrm{~GB}$ RAM with GAMS 24.8 for the Reference case. Subsequent model runs, departing from the previous solution, take approximately $20 \%$ less time than in the Reference scenario.

In the Reference scenario, electricity production in Denmark by 2050 would mostly be supplied by wind and solar photovoltaic (PV), with minor contributions from biomethane plants and waste incineration cogeneration facilities, as shown in Figure 8. Incineration plants would run almost at a steady level, due to the need to get rid of waste and the limited storage possibility -it is assumed that $50 \%$ of the industrial waste could potentially be stored but household waste cannot- as well as to minimize over-dimensioning of the plants, which are capitally intensive (Pizarro-Alonso, Cimpan, Söderman, Ravn, \& Münster, 2018). Wind and solar intermittencies would be balanced through gas cogeneration plants and electricity trade with neighboring countries (see Figure 9). Due to the existence of planning constraints as well as land limitations when investing in new wind farms, there is a maximum technical potential for onshore and offshore wind deployment in Denmark, as estimated in the "Nordic Energy Technology Perspectives" (Norden; IEA, 2016). The maximum potential for onshore wind in Denmark is reached, but the potential for offshore technology, $133 \mathrm{GW}$, is significantly larger than the installed capacity in the Reference scenario, 5.4 GW. 
Heat pumps would provide approximately $46 \%$ of the total district heating demand in Denmark by 2050, waste incineration around $26 \%$, and excess heat from industries, biorefineries and electrolyzers almost $20 \%$. Gas cogeneration plants running on biomethane fuel would satisfy up to $9 \%$ of the total district heating demand, driven by the requirements on back-up power capacity. Excess heat and incineration plants would supply the base-load demand. Heat pumps and heat-storage would balance the system, as illustrated in Figure 9, in order to minimize electricity imports when the residual electricity demand is high and to limit investments in heat pumps.
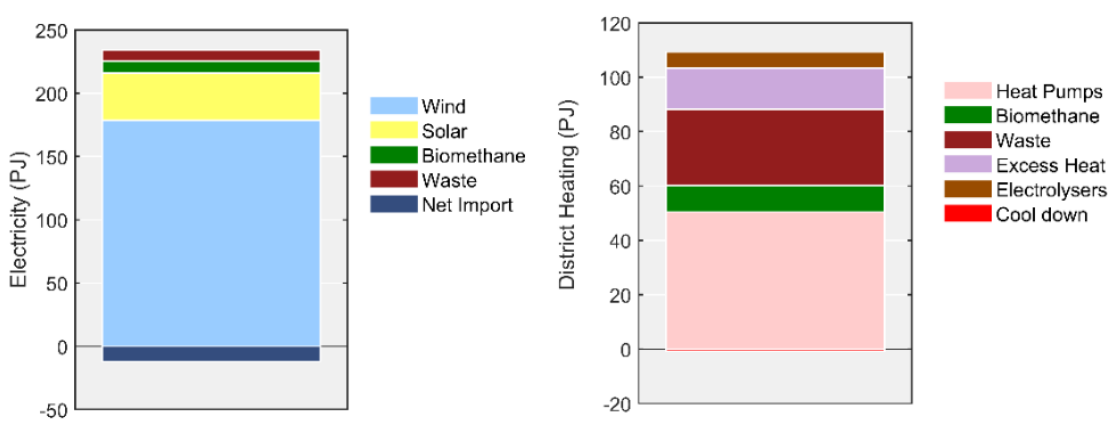

Figure 8. Electricity and district heating production in Denmark by 2050 - Results from the Reference scenario in Balmorel. A negative value in net imports of electricity means that the country exports more electricity than it imports at an annual level.
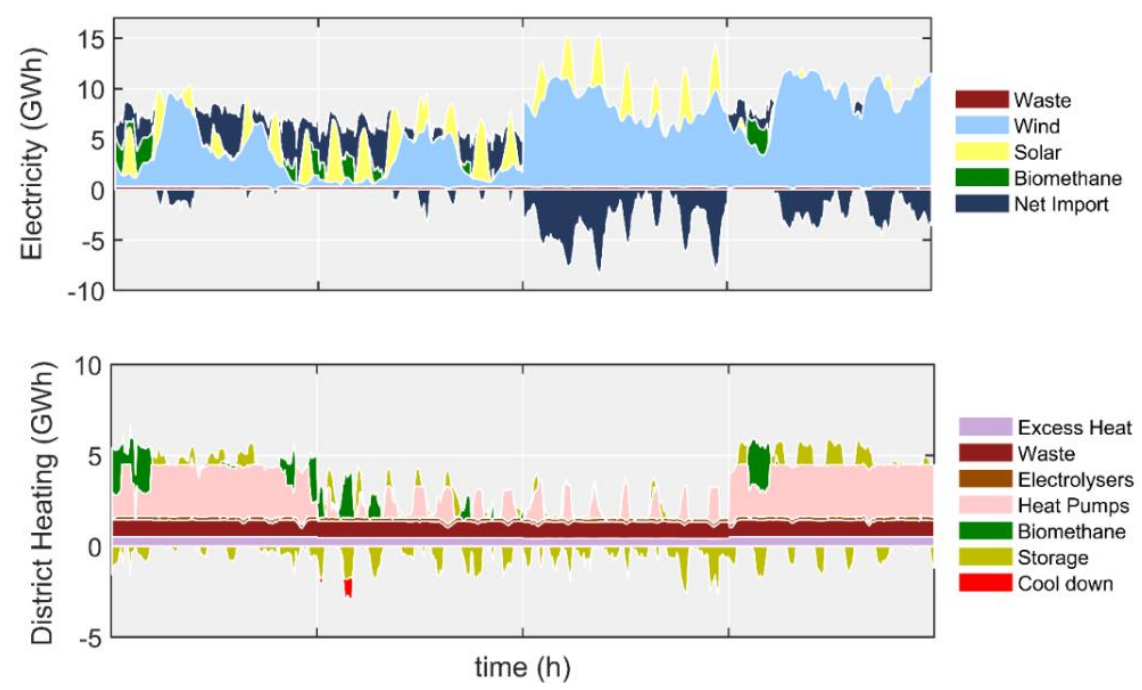

Figure 9. Hourly electricity and district heating production in Denmark by 2050 -672-time steps (1-time step = 1 hour in this study), 1 representative full week of each season-Results from the Reference scenario in Balmorel.

\subsection{Global Sensitivity Analysis (GSA)}

\subsubsection{GSA on electricity prices}

Based on the input parameter uncertainties, defined in Table 1, Morris sampling resulted in 1295 deterministic model runs. The sigma-scale elementary effects for each of the 36 uncertain input parameters are calculated using Equation 2 and 3. The $r$ sigma-scaled elementary effects of the annual Danish electricity prices are plotted as histograms in Figure 10 for a number of selected parameters, so as to exemplify the subsequent construction of Figure 11 . The larger the absolute value of $\mu_{i}^{S E E}$, the more the parameter $i$ contributes to the output uncertainty. A small $\sigma_{i}^{S E E}$ indicates that the effect of its perturbation in the output will be the same, independently of other possible uncertainties. A large $\sigma_{i}^{S E E}$ reflects that there are interactions with at least one other parameter. 

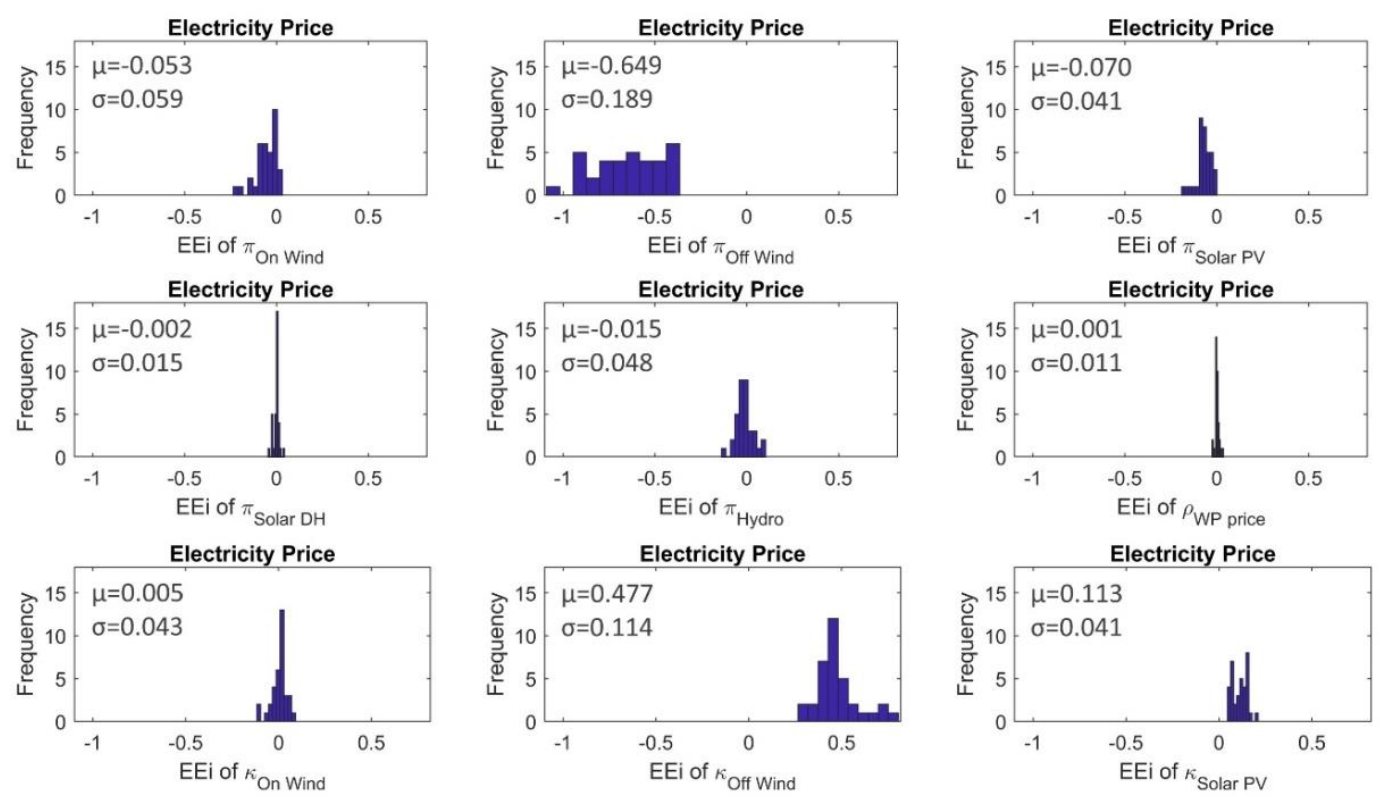

Figure 10. Histogram of the distribution of the sigma-scaled elementary effects of nine selected input parameters on the weighted average annual Danish electricity price in Balmorel, $r=35$ random observations of $E_{i}$.

The uncertainty on some input parameters, such as the capacity factors of hydropower plants or photovoltaic panels $\left(\pi_{\text {Hydro }}, \pi_{\text {Solar DH }}\right.$ ), capital costs of onshore wind turbines $\left(K_{\text {On Wind }}\right)$, or wood pellets prices ( $\rho_{\mathrm{WP}}$ price $)$ has a negligible impact on electricity prices, as their $E E \mathrm{~s}$ are practically zero in Figure 10. However, the other parameters represented in Figure 10 affect to a different degree the output. The distribution of $E E \mathrm{~s}$ of the parameter of wood pellets price ( $\rho_{\mathrm{WP}}$ price) presents a standard deviation of almost zero, which indicates that its effect on electricity price is not affected by the uncertainty of other parameters. However, the effect on the output from the uncertainty of other influential parameters depends on the variation of other uncertain parameters; especially the capacity factor of offshore wind turbines ( $\pi_{\text {Off Wind }}$ ), which is the parameter with the largest standard deviation of $E E$ s on the average annual electricity price.

The mean and the standard deviation from the distribution of the sigma-scaled elementary effects, $S E E_{i}^{r}$, are calculated and they are plotted in Figure 11. In each subplot, each cross represents the estimated mean and standard deviation of the elementary effect of the parameter labeled next to it. If a parameter (i.e. the cross) lies inside the wedge of the two lines $\left( \pm \operatorname{sem}_{i}, \sigma_{i}\right)$ (see Equation 4), its effect on the output is negligible and can be deemed as insignificant. On the contrary, if a parameter lies outside the two lines of the standard-error-of-the-mean wedge, the uncertainty on it has a significant impact on the output.

Graphical results from the Morris screening shown in Figure 11 point out to 21 significant parameters on long-term Danish electricity prices: capacity factors of offshore and onshore wind turbines, and photovoltaic panels ( $\pi_{\text {Off Wind }}, \pi_{\text {On Wind }}, \pi_{\text {Solar PV }}$ ); the discount rate $(\mathrm{DR})$; capital costs of offshore wind turbines, photovoltaic panels, alkaline electrolyzers, gas engines and inter-seasonal heat storage ( $\mathrm{K}_{\text {off }}$ Wind, $\mathrm{K}_{\text {Solar PV }}, \mathrm{K}_{\mathrm{AEC}}, \mathrm{K}_{\text {Heat St-L}}, \mathrm{K}_{\mathrm{Gas}}$ Eng); availability of municipal solid waste and biogas (upgraded to biomethane quality) for electricity and district generation in Denmark ( $\mu_{\mathrm{MSW}}, \mu_{\text {Biogas }}$; ; electricity demand in Denmark, Sweden and Finland, and transport electrification as well as district heating demand in Denmark ( $\left.\delta_{\text {Elec DK }}, \delta_{\text {Elec SE }}, \delta_{\text {Elec FI }}, \delta_{\text {Elec DK-EV }}, \delta_{\text {DH DK }}\right)$; availability and investments in power transmission lines $\left(\tau_{\text {availability }}, \tau_{\text {Inv Lim, }}, \tau_{\text {Inv Cost }}\right.$ ); and efficiencies associated to alkaline electrolyzers and heat pumps $\left(v_{\mathrm{AEC}}, v_{\mathrm{HeatPump}}\right)$ (see Table 1$)$. All the parameters considered significant are interrelated as their standard deviations (the y-axis on Figure 11) are different from zero. This highlights the 
importance of conducting a global sensitivity analysis to identify the parameters that could affect the results the most.

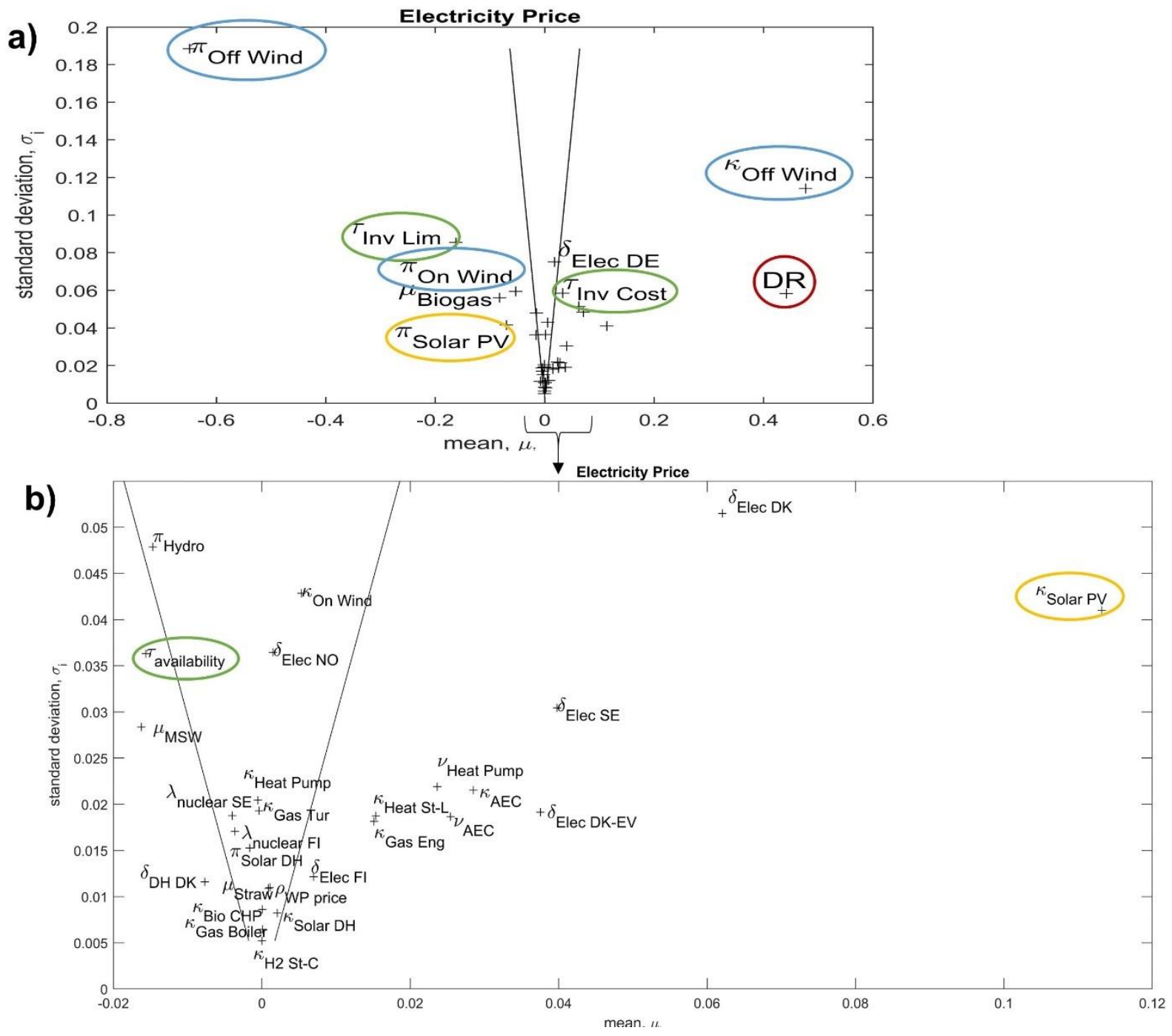

Figure 11. Estimated mean and standard deviations of the distribution of elementary effects of the 36 input parameters on the weighted average electricity prices in Denmark by 2050, where b) is a zoomed part of a)-plot. An influential parameter must be within the two lines in each subplot, which correspond to mean $= \pm$ sem $_{i}$ (see section 2.1, Eq. 4). The circles highlight some of the parameters discussed in the manuscript.

Nowadays, the main drivers of electricity prices, which reflect short-term costs, are mainly related to fossil fuel prices, $\mathrm{CO}_{2}$ taxes and power transmission limits, such as bottlenecks (Dansk Energi, 2018). Long-term prices indicate the socio-economic cost associated to the production of one unit more of electricity, including capital costs if there is not enough installed capacity to satisfy an increase in an additional unit of demand, but being equivalent to the short-term prices for most of the time steps. The parameters affecting results the most are the capacity factor and capital costs of offshore wind turbines. Higher capacity factors or lower capital costs would promote the deployment of wind technologies in the Balmorel model, whose objective function seeks to minimize the total cost for satisfying a given demand. In turn, higher offshore wind capacity would allow decreasing annual average electricity prices, as wind would have a bidding price of zero in the short-term market. The capital cost of onshore wind does not affect significantly electricity prices, so despite the fact of its uncertainty, as defined in Table 1, the onshore wind potential would be exploited in Denmark. 
The effect of the parameters affecting Danish long-term electricity prices most significantly is summarized below:

- Learning rates on offshore wind turbines might play a very important role in decreasing electricity prices by 2050 . Therefore, there should be a focus on decreasing the cost of the wind turbine itself, as well as its installation, operation and maintenance, and on increasing capacity factors. Furthermore, the development of a mature offshore wind market will increase the efficiency of the collaboration among different players and promote competition, which might decrease even further offshore wind costs.

- Lower capital costs of photovoltaic solar cells would allow a larger deployment of the technology in spite of low solar irradiation levels (compared to other countries, e.g. in Europe, Cyprus, Malta and Spain had on average 50\% larger irradiation levels during the period 19852016 than Denmark) (Pfenninger \& Staffell, 2016). Since capacity factors of wind turbines are higher during the night and wintertime in the North Sea area, and solar PV only produces during the day, especially during summertime, the two technologies could supplement each other, decreasing the need for electricity imports at higher prices. This seasonal match to demand has also been pointed out by Creutzig, et al. (2017). This would yield a more diversified electricity matrix and a decrease in electricity prices. Therefore, in spite of the fact that some countries have relatively low solar irradiation levels and large wind resource potentials, such as e.g. the Nordic and Baltic countries, Great Britain, and Ireland; solar PV could supplement in a cost-efficient way wind deployment, especially with larger technological developments.

- Proper market mechanisms must be introduced to reduce the risk of investments assessed by investors, which could promote the acceptance of lower returns. This could have a significant impact on electricity prices, promoting investments in technologies which are more capitally intensive, but have no variable operational cost, such as solar and wind.

- Denmark is not an isolated system but rather a part of an increasingly larger power market, where the electricity price is set. Neighboring countries affect Danish electricity prices significantly, from two angles: transmission capacity and electricity demand. On one hand, larger investments in transmission capacity would lead to lower electricity prices in the long term, as Denmark would be able to integrate larger shares of variable renewable energy and to balance their production with cheaper imports. On the other hand, increases in electricity demand in neighboring countries would increase Danish electricity prices. This shows the importance of taking inter-regional approaches regarding energy planning, and to establish goals and policies, e.g. in energy efficiency and transmission capacity, at European level.

\subsubsection{GSA on district heating prices}

Results from the Morris screening on district heating prices, illustrated in Figure 12, identify 15 significant parameters: capacity factors of offshore and onshore wind turbines $\left(\pi_{\text {Off Wind, }}, \pi_{\text {On Wind, }}\right.$, ; the discount rate (DR); capital costs of heat pumps, offshore wind turbines, photovoltaic panels, alkaline electrolyzers, and inter-seasonal heat storage ( $\mathrm{K}_{\text {Heat Pump }}$, $\left.\mathrm{K}_{\text {Off Wind, }} \mathrm{K}_{\text {Solar PV }}, \mathrm{K}_{\mathrm{AEC}}, \mathrm{K}_{\text {Heat St-L}}\right)$; availability of municipal solid waste and biogas $\left(\mu_{\mathrm{MSw}}, \mu_{\text {Biogas }}\right)$; district heating demand in Denmark, and electricity demand in Denmark and Sweden $\left(\delta_{\mathrm{DH}} \mathrm{DK}, \delta_{\mathrm{Elec}} \mathrm{DK}, \delta_{\mathrm{Elec}} \mathrm{SE}\right)$; limits to the investments in power transmission lines $\left(\tau_{\text {Inv Lim }}\right)$; and efficiencies associated to heat pumps $\left(v_{\text {HeatPump }}\right)$. All of them are also significant for electricity prices, excepting the capital cost of heat pumps, $\mathrm{K}_{\text {Heat }}$ Pump. The reason why there are 14 parameters that affect both electricity and district heating prices significantly is because electricity and district heating markets are and will become increasingly interconnected, as 
depicted in Figure 9. Furthermore, all the parameters deemed as significant are also interrelated, as their standard deviations are different from zero.
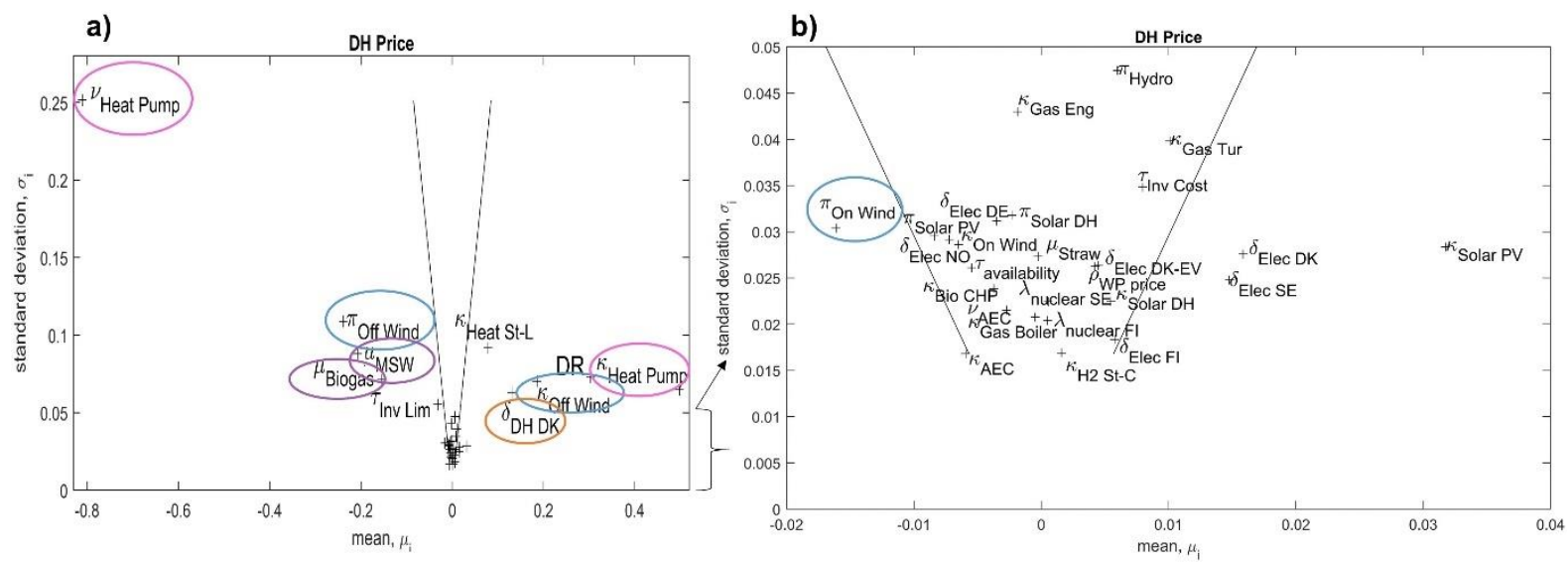

Figure 12. Estimated mean and standard deviation of the distribution of elementary effects of the 36 input parameters on the weighted average district heating prices in Denmark by 2050, where b) is a zoomed part of a)-plot. An influential parameter must be within the two lines in each subplot, which correspond to mean $= \pm$ sem $_{i}($ see section 2.1, Eq. 4). The circles highlight some of the parameters discussed in the manuscript.

Long-term Danish district heating prices would be significantly sensitive to actions and policies with regards to some of the parameters summarized below:

- As shown in Figure 9, the role of heat pumps in the future district heating supply is very large, satisfying almost half of the demand. Therefore, the coefficients of performance (COP) as well as capital costs of heat pumps are important in order to ensure cheap district heating prices. The use of heat pumps that operate with a lower source-sink temperature difference, leading to an increased efficiency, should be promoted as well as research that focuses on technological improvements.

- The large electrification of the district heating supply by heat pumps emphasizes the importance of the development of more efficient and cheaper offshore wind technology, i.e. the access to cheaper electricity prices to ensure also lower district heating prices.

- Efficiency improvements that could lead to a demand reduction would not only decrease the total cost of satisfying the end-use demand, but would also impact markets, thereby decreasing district heating prices for all consumers. Therefore, the analysis of proper regulatory frameworks that promote or enforce efficiency targets is important.

- A larger availability of municipal solid waste and biogas, which is subsequently upgraded to biomethane quality, would decrease district heating prices by minimizing the use of heat pumps when electricity prices are high and vice versa. Therefore, the allocation of waste and biomass resources for electricity, district heating and fuel production would impact heating prices.

\subsubsection{GSA on wind capacity deployment in Denmark}

The are 22 parameters having a significant influence on the wind deployment in Denmark, as shown in Figure 13, which are: capacity factors of offshore wind turbines, hydropower plants and photovoltaic panels $\left(\pi_{\text {Off Wind }}, \pi_{\text {Hydro }}, \pi_{\text {Solar PV }}\right.$ ); capital costs of photovoltaic panels, gas turbines and inter-seasonal heat storage $\left(\mathrm{K}_{\text {Solar PV }}, \mathrm{K}_{\text {Gas Tur }}, \mathrm{K}_{\text {Heat St-L }}\right)$; availability of municipal solid waste and biogas for electricity and district generation in Denmark $\left(\mu_{\mathrm{MSW}}, \mu_{\text {Biogas }}\right)$; electricity demand in 
Denmark, Sweden, Norway and Finland, and transport electrification as well as district heating demand in Denmark ( $\left.\delta_{\text {Elec DK }}, \delta_{\text {Elec SE}}, \delta_{\text {Elec NO}}, \delta_{\text {Elec FI }}, \delta_{\text {Elec DK-EV }}, \delta_{\text {DH DK }}\right)$; availability and investments in power transmission lines $\left(\tau_{\text {availability }}, \tau_{\text {Inv Lim }}, \tau_{\text {Inv Cost }}\right.$ ); efficiencies associated to alkaline electrolyzers and heat pumps $\left(v_{\mathrm{AEC}}, v_{\text {HeatPump }}\right)$; evolution of nuclear capacity in Finland and Sweden $\left(\lambda_{\text {nuclear FI, }}, \lambda_{\text {nuclear }}\right.$ $\mathrm{SE})$; and wood pellets price ( $\rho_{\mathrm{WP} \text { price }}$ ) (see Table 1$)$.
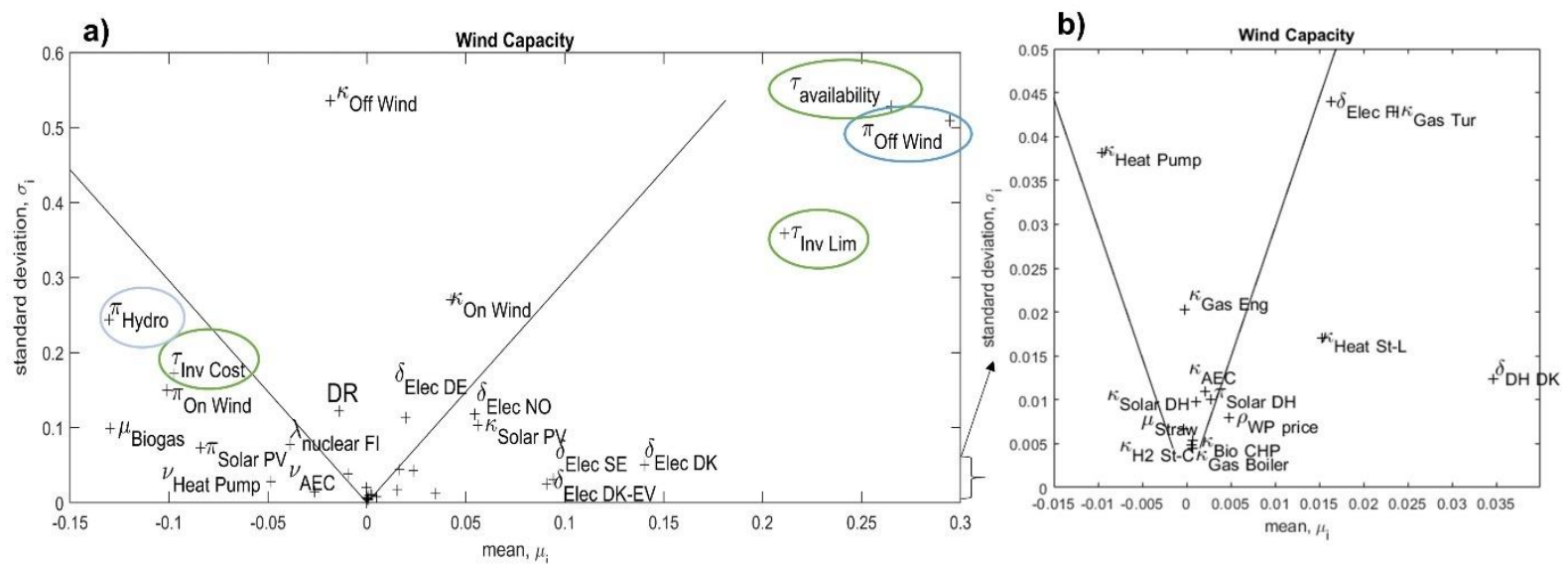

Figure 13. Estimated mean and standard deviation of the distribution of elementary effects of the 36 input parameters on the installed capacity of onshore and offshore wind power in Denmark by 2050, where b) is a zoomed part of a)-plot. An influential parameter must be within the two lines in each subplot, which correspond to mean $= \pm$ sem $_{i}$ (see section 2.1,

Eq. 4). The circles highlight some of the parameters discussed in the manuscript.

The deployment of wind farms will be driven by a combination of different parameters, where an increase in the efficiency of wind turbines could largely raise investments. Moreover, as indicated in the Danish Energy Agreement from 2018, a successful expansion of offshore wind will require that the electricity transmission infrastructure is conveniently upgraded at an international level. This will enable exports of large volumes of wind-based electricity when there is surplus, and imports when there is a deficit due to high residual demands. As Figure 13 shows, an increase in the demand, not only in Denmark but in the Nordic countries, could be balanced by an increase in installed capacity in offshore wind in Denmark, if proper transmission lines are built.

The amount of electricity generated by hydropower plants would also affect wind capacity, as if it decreases, e.g. due to less precipitations or snow melt, and increase in wind capacity could balance it, and vice versa.

\subsection{Uncertainty Analysis}

\subsubsection{Quantification of the uncertainty on electricity and district heating prices}

Based on results from Morris sampling, Monte Carlo simulations were first conducted for the 22 input parameters whose uncertainty was considered influential for the electricity and district heating sectors in the previous subsection. The Latin Hypercube Sampling method was applied for generating samples of $\theta_{10 \times 22}, \theta_{15 \times 22}, \theta_{25 \times 22}, \theta_{50 \times 22}, \theta_{100 \times 22}$ and $\theta_{200 \times 22}\left(\theta_{N \times 22}\right)$ (see section 2.2). Running Monte Carlo simulations in the Balmorel model resulted in $N$ results for each output, shown in Figure 14. Results were statistically evaluated by using a confidence interval of 99\%, as shown in Figure 15. It must be noted that high uncertainty in the prices is not synonymous with low quality of the Balmorel model, but a result of the stochastic variability of the inputs. It would be more accurate to communicate the uncertainty range rather than stating the mean. The number of Monte Carlo runs, i.e. $N$, does not affect significantly the mean of electricity and district heating prices, even with a small number of samples. 

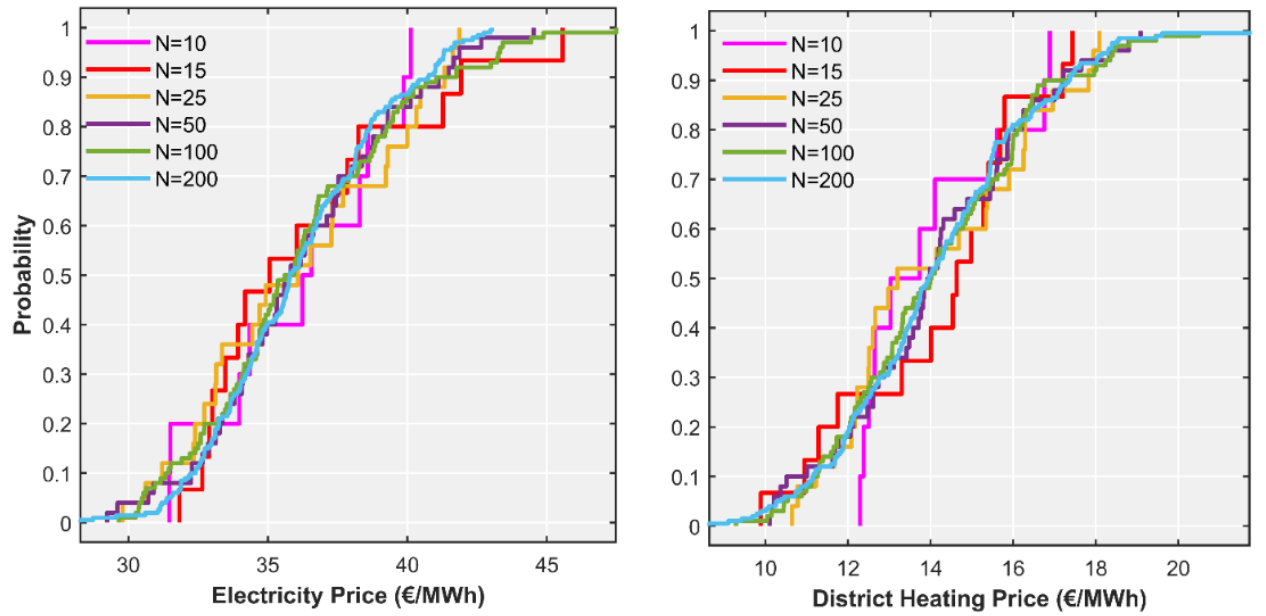

Figure 14. Impact of N Monte Carlo simulations on the cumulative distribution function of electricity and district heating prices.
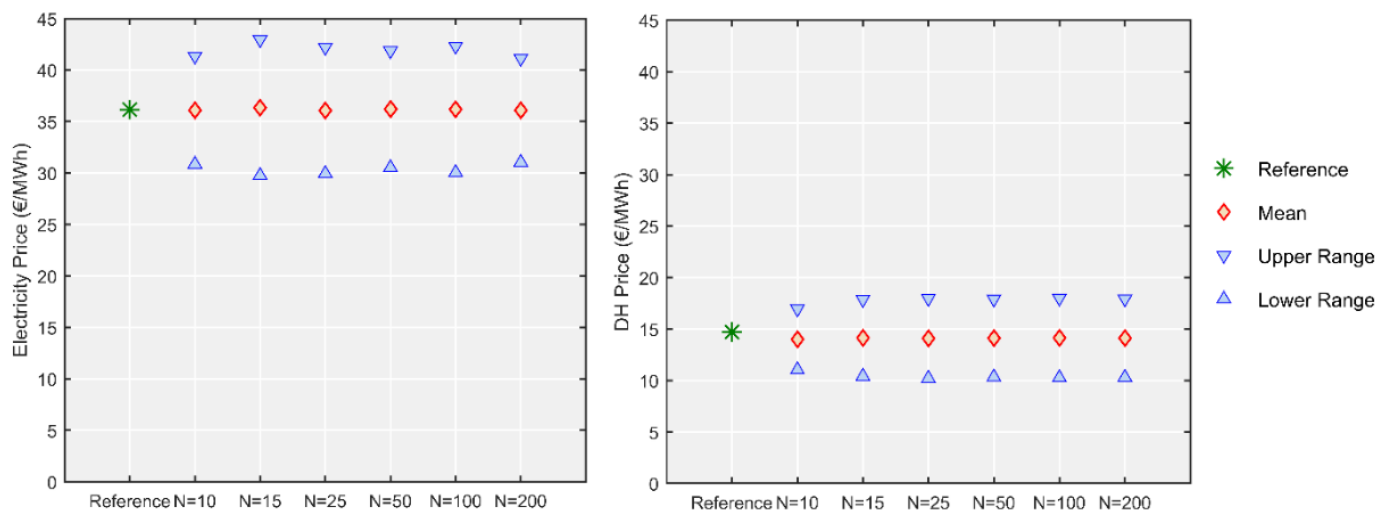

Figure 15. Impact of N Monte Carlo simulations on the $99 \%$ confidence interval of Danish electricity and district heating prices, i.e. truncated distribution functions to \pm 3 standard deviations from the mean.

In Figure 14, there is a higher range on the right side, i.e. higher than the mean value, than on the left side, for both electricity and district heating prices. For this reason, the skewness and kurtosis of the cumulative distribution functions are calculated (see Table 2). For both electricity and district heating prices, the cumulative distribution functions are generally skewed to the right (positive skewness): the tail on the curve's right hand side, i.e. high prices, is longer than the tail on the left-hand side, i.e. lower prices, and the mean is greater than the mode, i.e. in a larger amount of runs prices are lower than the mean. The kurtosis of the cumulative distribution functions is low, which means that data from the tails are generally less extreme than in a normal distribution, whose kurtosis is 3 . It could indicate that the perceived risk to deviate from the mean value would not be relatively high, and similar for both electricity and district heating prices. 
Table 2. Skewness and kurtosis of cumulative distribution functions of electricity and district heating prices depending on N Monte Carlo simulations (* kurtosis following the non-excess convention).

\begin{tabular}{|l|cc|cc|}
\hline & Skewness & & \multicolumn{3}{l|}{ Kurtosis* } & \\
\cline { 2 - 5 } & Electricity Price & DH Price & Electricity Price & DH Price \\
\hline $\mathbf{N = 1 0}$ & -0.2 & 0.7 & 1.7 & 1.9 \\
$\mathbf{N}=\mathbf{1 5}$ & 0.9 & -0.4 & 2.9 & 2.2 \\
$\mathbf{N}=\mathbf{2 5}$ & 0.1 & 0.3 & 1.7 & 1.8 \\
$\mathbf{N}=\mathbf{5 0}$ & 0.2 & 0.2 & 2.6 & 2.4 \\
$\mathbf{N}=\mathbf{1 0 0}$ & 0.6 & 0.3 & 3.0 & 2.6 \\
$\mathbf{N = 2 0 0}$ & 0.2 & 0.2 & 2.5 & 2.9 \\
\hline
\end{tabular}

Graphical techniques could also be useful to estimate the sensitivity of the model towards a parametric perturbation. As Saltelli et al. (2008) say "a uniform cloud of points could be a symptom (though not a proof) of a non-influential factor". The scatterplots of electricity prices against some parameters with the largest influence, as identified by Morris sampling, are shown in Figure 16, and display different behaviors. The scatter plot of offshore wind capacity factor shows a downwards pattern, and the graph of offshore wind capital expenditures might seem slightly upwards when performing a higher number of repetitions. Nevertheless, in the plot related to limitations in the investment in new power transmission capacity is not possible to detect any trend among them. The interpretation of the impact of these parameters could be regarded as an indicator of non-linearity between the modeling output, i.e. electricity prices, and variations in the input parameters. This stresses the need to perform independently global sensitivity analyses and uncertainty analyses to avoid underestimating influential parameters.
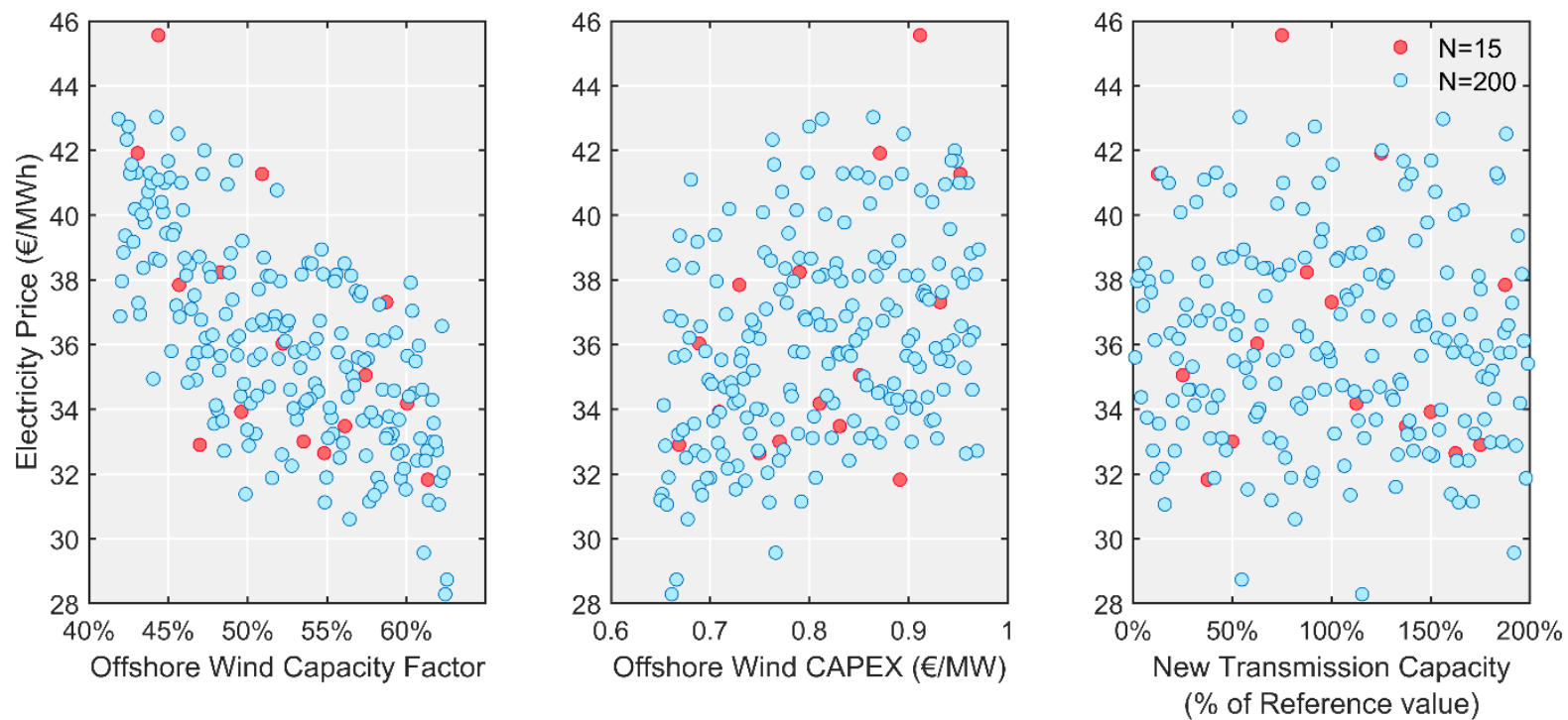

Figure 16. Scatterplots of the most-influential parameters from the Morris sampling compared to weighted average annual electricity prices.

In Figure 17, cobweb plots are used to visualize the simulations as a set of trajectories that connect the value of each parameter in each run, highlighting those leading to the largest and lowest values of electricity prices (Kurowicka \& Cooke, 2006). The lowest electricity prices, i.e. green lines in Figure 17 , are associated to high capacity factors and low capital costs of offshore wind ( $\pi_{\text {Off Wind }}, K_{\text {Off Wind }}$ ), 
and low discount rates (DR), and vice versa for the highest electricity prices, i.e. red lines. The interrelations among them are responsible to drive the model output into their extreme ranges.

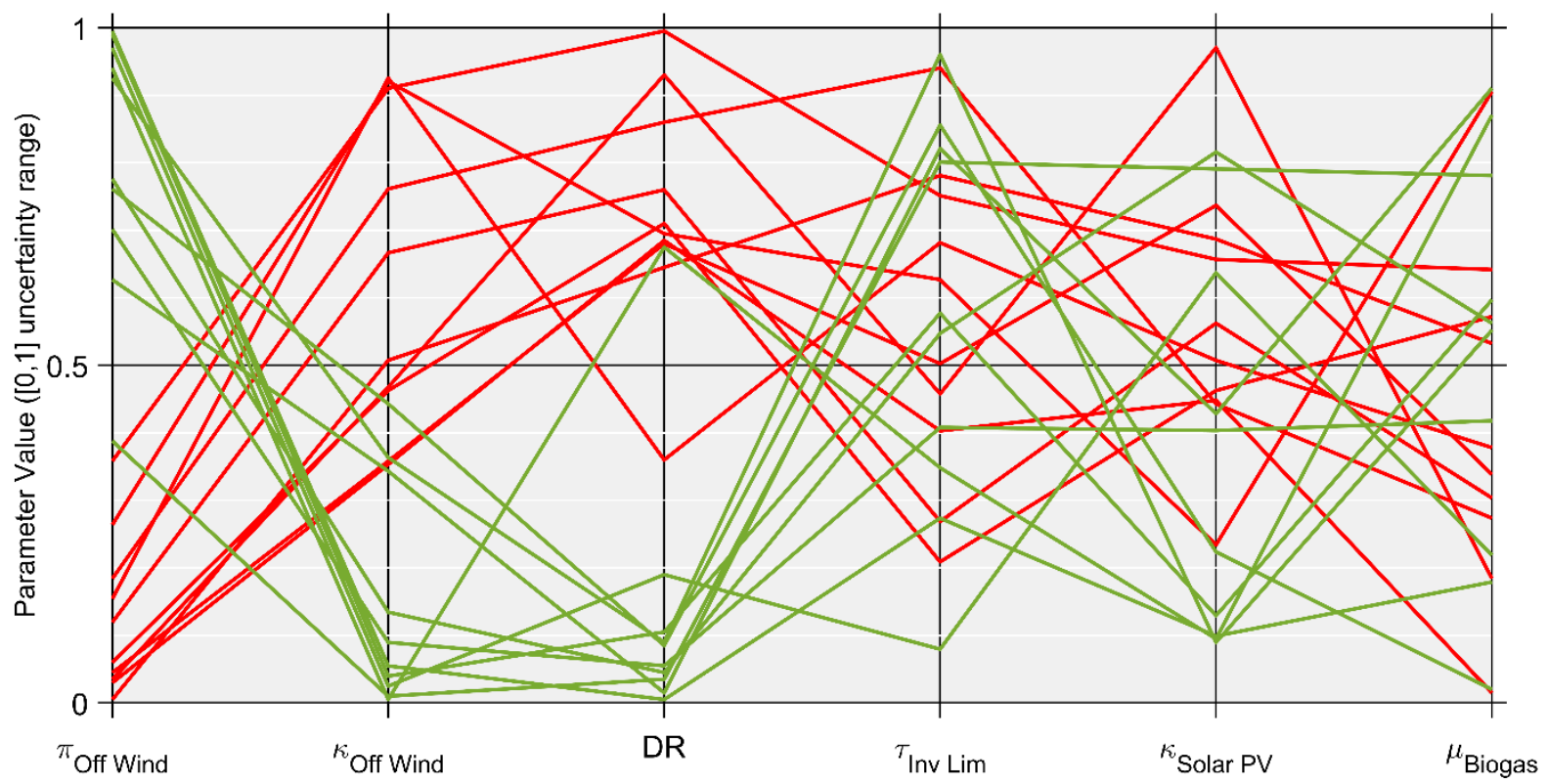

Figure 17. Cobweb plot of N=200 Monte Carlo simulations of electricity prices, depicting the six parameters ranked with the highest influence in the Morris sampling (green lines: 5\% lowest electricity prices, red lines: 5\% highest electricity prices). Each line represents a scenario, and the values of the six selected parameters according to the Latin Hypercube Sampling.

\subsubsection{Quantification of the uncertainty on wind capacity deployment}

When performing 100 Monte Carlo simulations varying the 22 parameters deemed as relevant in section 4.2.3, how uncertainty could influence the development in the electric power sector is assessed, as shown in Figure 18. Large investments in offshore wind are related to Denmark becoming a net annual exporter of electricity. Whenever wind-based power investments are smaller, solar PV capacity investments increase.

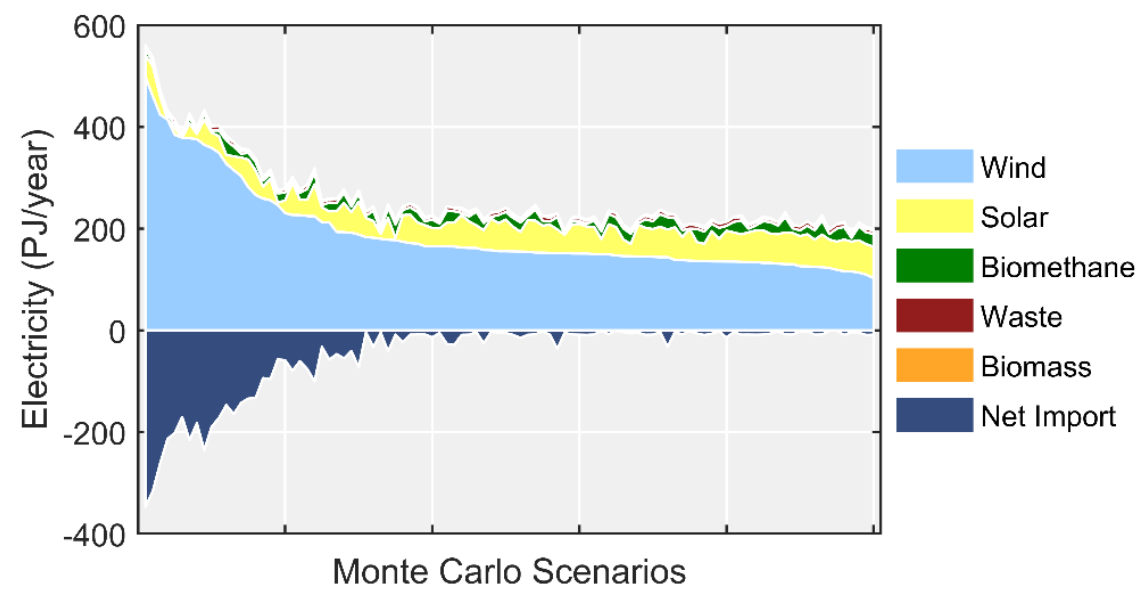

Figure 18. Annual Danish electricity generation in N=100 Monte Carlo runs by 2050, shorted by electricity generation from wind.

The lowest investments in wind capacity in Denmark would occur when the wind capacity factor is lower than expected and the possibilities to expand power transmission lines are smaller, as illustrated in the green lines of Figure 19. In this case, solar PV technologies become more cost-competitive, as 
they rely less on the transmission capacity, and would start playing an important role in the Danish power system. Despite the aforementioned, wind power production remains the main technology in all the 100 Monte Carlo runs, as solar and wind supplement each other well. The competition between wind and solar in regions with high wind resource potential but relatively low solar irradiation would not be driven so much by differences in technology costs, but on the possibility to use the power transmission grid or not; therefore, on the systems integration.

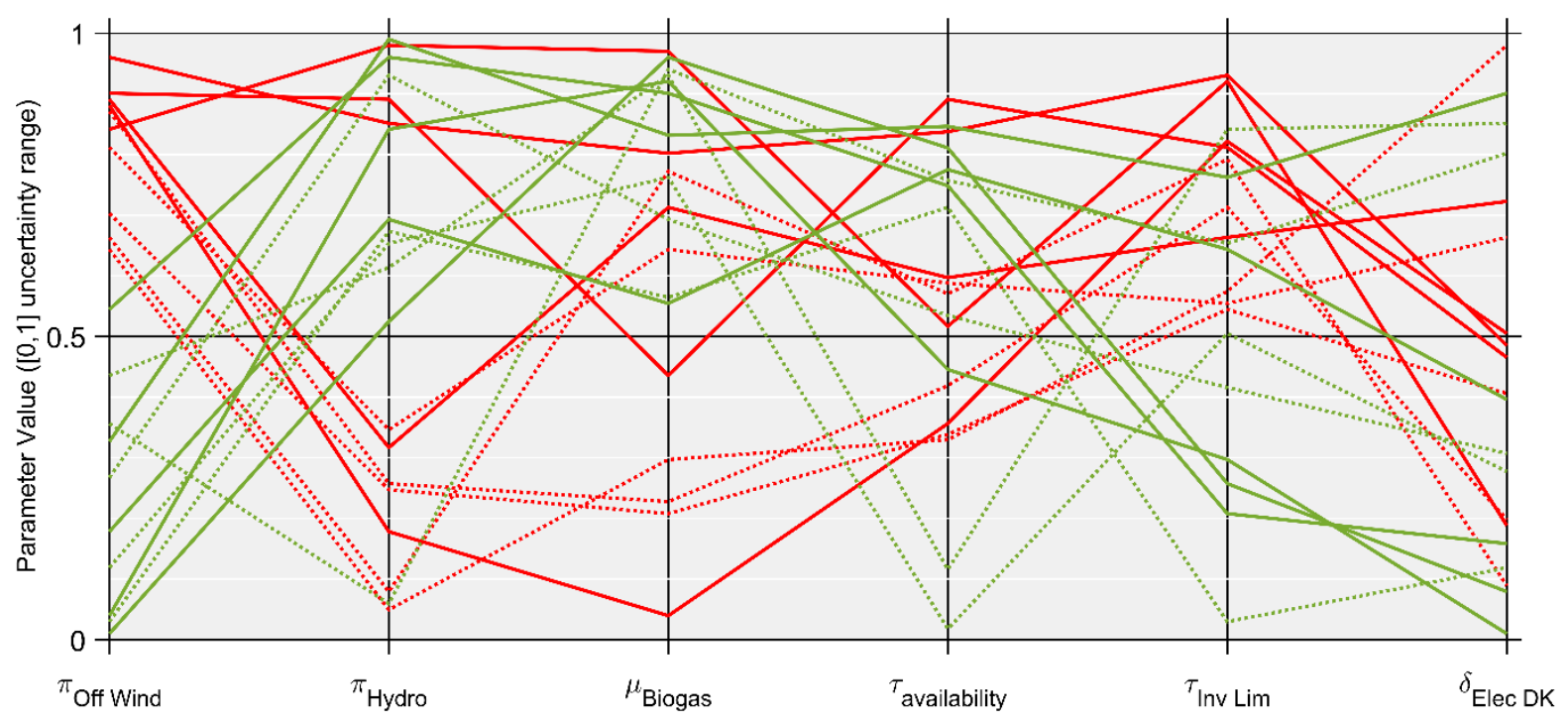

Figure 19. Cobweb plot of N=100 Monte Carlo runs of installed wind capacity in Denmark, depicting the six parameters ranked with the highest influence in the Morris sampling (green lines: 5\% lowest capacity, green dotted lines 5-10\% lowest capacity, red dotted lines: 5-10\% highest capacity, and red lines: 5\% highest wind capacity). Each line represents a scenario, and the values of the six selected parameters according to the Latin Hypercube Sampling.

\section{Discussion}

The world is undergoing rapid changes and there are many uncertainties that might impact the energy sector, such as economic, and population growth, technological development and climate change, which have a stochastic nature, i.e. due to an inherent variability rather than from a lack of knowledge. As Van't Klooster \& Van Asselt (2006) stated, "studying the future seems a mission impossible, since both the appearance of the future and its underlying dynamics are unknown and unknowable". In spite of the partially irreducible uncertainties, decisions have to be made regarding energy systems, aiming at reducing the undesired effects from uncertainty (Walker, et al., 2003), because "where the future is ill-defined, hardest to see, and pregnant with possibilities, our actions may well have their largest influence in shaping it" (Lempert, Popper, \& Bankes, 2003). The aim of this study is to contribute to have a deeper understanding of the incomplete and stochastic knowledge associated with the future energy system (Stirling, 2010).

Local sensitivity analyses, varying one factor at a time up and down around a reference value, are extensively used in energy systems modelling (Fais, Keppo, Zeyringer, Usher, \& Daly, 2016). Results, when applying this approach to this study, are shown in Figure 20, which shows that the capacity factor of offshore wind farms would be affecting electricity prices and wind deployment in Denmark the most. Furthermore, the COP of heat pumps would have a strong influence in Danish district heating prices. Nevertheless, other parameters deemed as significant in the global sensitivity analyses, and the cobweb plots from Monte Carlo simulations (Figure 17 and Figure 19), might appear as non-influential when omitting the effect of interaction between other parameters, e.g. the impact of limitations to the expansion of the power transmission grid. One-factor-at-a-time 
approaches cannot consider those interactions, and global sensitivity analyses are better suited for overcoming these shortcomings (Saltelli, et al., 2019) (Saltelli \& Annoni, 2010) in order to provide insight in the potential influence of all sorts of uncertainties in inputs, and to discriminate among parameters for the accuracy of the outcome. Nevertheless, although local sensitivity analyses might be limited to prioritizing which parameters affect results in a meaningful way, they play an important role in ensuring an understanding of the modeling complex systems dynamics; i.e. ascertaining cascading effects because of a change in a single parameter. The objectives of sensitivity analysis can be numerous, and model validation and understanding are important features, provided by one-factorat a time analyses. Hence, their use should still be recommendable, although their traditional scope must be re-considered.
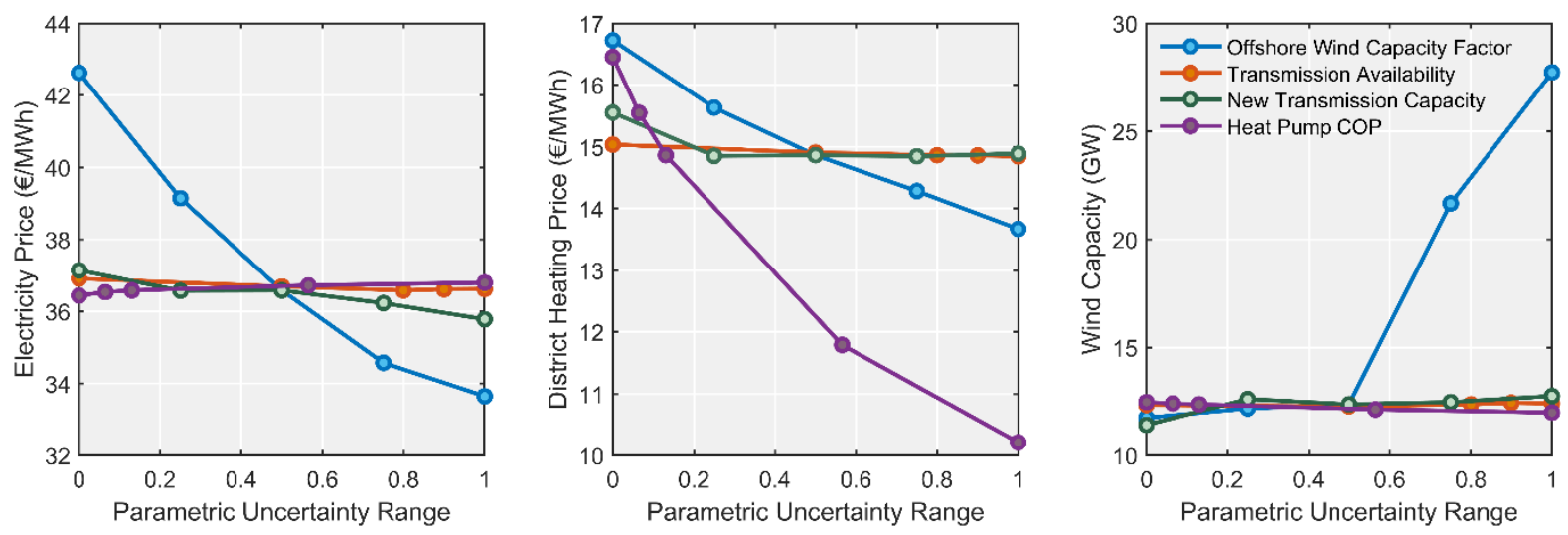

Figure 20. One-at-a-time sensitivity analysis from the unit hypercube uncertainty range (the Reference value does not have to correspond with the 0.5 of the range).

The advantages of the Morris screening over other methodologies for global sensitivity analyses are the requirement of less runs (see section 2.2.1). In this analysis, the impact of uncertainty from 36 input parameters is evaluated, a factorial design would imply more than $3.7 \cdot 10^{41}$ runs; however, using Morris sampling methodology 1295 runs (for $r=35$ ) are carried out. Nevertheless, it is important to mention that the computational cost associated with the Morris screening depends on the number of parameters considered, so it might also be computationally too demanding if the number of uncertain parameters is very large (Sin, Gernaey, \& Lantz, 2009).

If assuming that the uncertainties in model inputs are all stochastic, i.e. non-reducible, rather than epistemic due to a lack of knowledge; the uncertainty methodology applied in Balmorel helps to quantify how much we could deviate from the expected outcome. The global sensitivity analysis helps finding out which parameters contribute the most to that uncertainty. This also allows to establish priorities and facilitate debate with regard to promotion of technology developments for offshore wind turbines, importance of adequate energy policies for the increase of efficiency, enhancement of collaboration among countries in terms of power trade, etc. As Jouvenel expressed in "The art of conjecture" (1967), it is crucial to have visions about the future, based on clear reasoning, and by doing so, troubles can be detected before they arise, making changes in the desired direction.

Notwithstanding, the methodology used assumes "certain uncertainties", i.e. some estimates are available or have been assumed, although through educated guesses and literature review. In order to ensure the validity and relevance of the process, continuous feedbacks and the inclusion of a larger multidisciplinary group should be created. This group should have a broad view and be aware of possible biases. This might increase the quality of the exercises presented in this study, that prevent 
that relevant uncertainties are neglected, underestimated or overestimated, but bearing in mind the perils of group dynamics.

Global sensitivity analyses may also be used for guiding model development and simplifications, for focusing the representation and calibration efforts where it is critical in terms of driving model responses (Bosetti, et al., 2015). Our results highlight the importance of a detailed spatial disaggregation when modeling the electricity generation and the power trade as well as the possibility to use a less detailed spatial disaggregation for the district heating demand (see Figure 3). Furthermore, it focuses on an accurate representation of available heat sources, which could influence the efficiency of heat pumps, the parameter with the highest influence in future Danish district heating prices according to the results from the Morris sampling. Nevertheless, optimal location of waste-toenergy plants and biorefineries requires a very detailed geographical representation, which could be done in a previous step prior to the global sensitivity analyses.

Fais, et al. (2016) combined global sensitivity analysis in a bottom-up energy systems optimization model, TIMES, for a low-carbon United Kingdom by 2050, comprising all the sectors, e.g. including transport and industrial process heat demand, but without entailing a fossil-free system as in our study. They conducted the global sensitivity analysis with 32 scenarios that represent all possible combinations of five dimensions with two possible values $\left(2^{5}\right)$. Their results showed that decarbonization would be highly dependent on nuclear power plants and biomass carbon capture and storage. Renewables do not play a significant role in their reference case, although they can rise up to $97 \%$ of the electricity supply in 2050 in some of the scenarios. Nevertheless, given the fact that the nuclear power plant under construction in England, Hinkley Point $\mathrm{C}$, might have a cost of 92.5£/MWh, and that results from the second allocation round of the Contracts for Difference scheme for two offshore projects, Hornsea and Moray East windfarm, were of 57.5£/MWh (UK Department for Business, Energy \& Industrial Strategy, 2017), this might indicate that reference values and the scope could be updated. Similarly, Pye, Sabio \& Strachan (2015), also explored the uncertainties that would have most impact on the UK energy transition. Initially, they propagated the parametric uncertainty through a Monte Carlo approach, and then performed a global sensitivity analysis with scatterplots and multivariate linear regression analysis of selected results. They identified biomass availability, gas prices and nuclear capital costs as the most critical parameters, but uncertainties related to variable renewable energy and transmission grids were deemed as less influential elements.

Results from both studies suggest the need for using detailed spatial and temporal models when analyzing the parameters that might influence electricity generation the most, in order not to minimize the potential of variable renewable energy by dimensional aggregation of space and time, and to consider a wider range of possible uncertainties of renewable energy technologies. Bosetti, et al. (2015) focused their analysis in eight parameters related to solar and nuclear power, biofuels, bioelectricity, and carbon capture and storage. They performed a global sensitivity analysis with 740 runs for three different climate constraint scenarios with the global models WITCH and GCAM, and the regional model MARKAL-US. Bosetti, et al. (2015) identified the predominance of nuclear energy cost as the main source of variation among models, and subsequently, they highlighted the importance of exploring advanced nuclear possibilities and social acceptance of the technology. Nevertheless, some pathways that limit the warming to $1.5^{\circ} \mathrm{C}$ no longer see a role for nuclear fission by the end of the century due to societal preferences (Rogelj, et al., 2018).

Marcucci, et al. (2019) applied Monte Carlo analysis in a technology rich integrated model, MERGEETL, in order to analyze the effect of the parametric uncertainty in realizing the stringent target from the Paris agreement. The PROMETHEUS model produces joint empirical distributions of several variables, which are important for the evolution of the global energy system, such as population and 
economic growth, fossil resource potentials, technology performance and learning rates. The use of PROMETHEUS, for sampling of the joint probability distributions of the parameters, significantly differs from this study, in which the probability distributions of the uncertain inputs are ad hoc, mainly based on literature. Chen et al. (2017) found no report on interactions among multiple parameters in electric systems planning models; however, methodologies dealing with joint probability distributions might be recommended, as also suggested by Yu et al. (2018). Marcucci et al. (2019) found that the availability of biomass resources, the rapid decrease of the costs of renewables and improvements in energy efficiency were the factors with the largest effect on the cost of carbon on a global level. Our study also suggests that the capacity factors of variable renewable energy technologies and the possibility to integrate them efficiently, e.g. through an adequate transmission grid, would probably also have a large impact on the cost of carbon on a global level, as they do it in the Danish electricity prices of a fossil-free system.

Global sensitivity analysis could also be a way to screen parameters for performing a posteriori stochastic analysis with a reduced number of parameters. Some authors, such as Usher \& Strachan (2012), indicated that results from stochastic optimization might be very different from the average of the deterministic scenarios, illustrating pathways that would seek to minimize risk, and thus providing valuable information.

For all the above mentioned, uncertainty and sensitivity analyses should play an essential role when using energy models and correctly interpreting and communicating their results, even when models have a very detailed spatiotemporal resolution for capturing short-term dispatch dynamics. As demonstrated in this study, mature analysis methods exist for dealing with input uncertainty, this being the main challenge the computational burden. Nevertheless, the importance of energy scenarios should not be disregarded when coherent and structured pictures about the future are created. Policy makers would get on the one hand, a clear and concise message, but on the other hand, a conditional advice, which would enable a plural policy debate (Stirling, 2010).

Scenarios provide order and meaning to events and decisions; and the audience, including nonenergy- modeler experts can easily follow their pathways, i.e. the effects of parameters in the outcome. In addition, they avoid the risk of providing a sense of "false exactness", which might grow from bias when estimating probabilistic functions. Human judgment remains crucial for decisionmaking, and scenarios are a powerful tool for communication, suitable for the purpose of helping people to image desirable futures and to take proper actions to achieve them (Onkal, Sayim, \& Gonul, 2013). Their relevance and adequacy might improve by integrating the quantitative approach of global sensitivity analysis prior to the construction of scenarios, which would highlight the main parameters to bring them into focus when building narratives, rather than using a purely heuristic prioritization. It should, however, be borne in mind that scenario building is not a reductionist process, but an "art like storytelling" including a plurality of views (Wilk, 1991) (Mahony, 2014).

\section{Conclusions}

Diverse uncertainties might influence the long-term planning of the energy sector, such as economic and population growth, technological development, climate change, etc. Most of these uncertainties are owing to an inherent variability of long-term forecasts and cannot be reduced. However, they can be, and should be, characterized. Energy models are used as support tools for decision-making processes, and knowledge of the uncertainty might help to reduce the undesired effects thereof and help to provide robust solutions. In an attempt to address uncertainties, most studies explore different alternative scenarios or perform local sensitivity analysis, altering one factor at a time. However, the 
effect of interrelations between parameters is not properly considered, and other approaches are necessary in order to deal with these shortcomings. A methodology, for dealing with stochastic input uncertainty over different combinations of the uncertainty space but keeping the solution of the model as deterministic, is described and applied. As a novelty, this study assesses the impact of uncertainty in systems with a large potential of integration of high shares of wind-based electricity; therefore, models with a detailed spatiotemporal representation are required. The Balmorel model is used for long-term planning of a Danish fossil-free electricity and district heating generation by 2050, as an example of a country with large offshore wind resources. The applied methodology for describing the parametric uncertainty involves three stages:

1. Pre-selection of the parameters that might affect results the most and characterization of their uncertainty, based on literature search and expert review.

2. Global sensitivity analysis through Morris sampling to identify and rank all the influential parameters as well as the interrelations between them.

3. Uncertainty analysis using Monte Carlo simulation with Latin Hypercube Sampling, with a subsequent statistical evaluation.

In the first step, 36 parameters were deemed relevant for inclusion in this study. Results from global sensitivity analyses identified critical parameters, which supports research prioritization and the definition of scenarios as well as model development and simplification. Electricity prices would mainly be affected by the improvement of offshore wind technology, capital costs of solar photovoltaic panels, development of the transmission power grid and discount rates. Therefore, countries or regions with large offshore wind potentials and the possibility to increase power transmission in cooperation with other countries and regions (e.g. through an adequate policy framework), would greatly benefit from a larger improvement of the offshore wind technology, especially with higher capacity factors. However, technological development of solar photovoltaic systems is also important - in spite of the fact that some countries might have relatively low potentials - as it might support a more cost-efficient seasonal match to demand. District heating prices would be affected the most by the efficiency and cost of heat pumps, and thus also by the evolution of the electricity market.

According to the Monte Carlo runs, in regions with large offshore wind potential, if the grid infrastructure is not adequately upgraded, wind could be under-deployed, imposing higher societal costs. Offshore wind upscaling at high rates will depend not only on technological improvements, but increasingly on constraints of the system integration. Hence, large deployments of offshore wind would require policies that foster technological learning, but also that promote the cost-efficient integration of growing shares in the power mix.

Uncertainty and global sensitivity analyses should play an essential role when using energy models and communicating their results, because all the parameters identified as influential in the selected outputs were affected by the uncertainty of other parameters. Mature analysis methods exist for dealing with parametric uncertainty, as demonstrated in this study. The main challenge is the computational burden, especially in models dealing with high integration of fluctuating renewable energy; and thus having a very detailed spatiotemporal representation. Nevertheless, their ultimate reliability will depend upon a reasonable quantification of input uncertainty ranges, which should be further improved. 


\section{Acknowledgments}

The work reported in this article has been undertaken as part of the FutureGAS project, financed by the Innovation Fund Denmark (grant number 76084). Authors would like to thank Gurkan Sin (Department of Chemical and Biochemical Engineering - Technical University of Denmark) for the insights given regarding uncertainty and sensitivity analysis for numerical models.

\section{Appendix A. Supplementary material}

Supplementary data associated with this article can be found, in the online version.

\section{Bibliography}

Abdin, I. F., \& Zio, E. (2018). An integrated framework for operational flexibility assessment in multi-period power system planning with renewable energy production. Applied Energy, 222, 898-914.

Babrowski, S., Heffels, T., Jochem, P., \& Fichtner, W. (2014). Reducing computing time of energy system models by a myopic approach. Energy Systems, 5, 65-83.

Balyk, O., Andersen, K. S., Dockweiler, S., Gargiulo, M., Karlsson, K., Næraa, R., . . Venturini., G. (2019). TIMES-DK: Technology-rich multi-sectoral optimisation model of the Danish energy system. Energy Strategy Reviews, 23, 13-22.

Barragán-Beaud, C., Pizarro-Alonso, A. R., Xylia, M., Syri, S., \& Silveira, S. (2018). Carbon Tax or Emissions Trading? An Analysis of Economic and Political Feasibility of Policy Mechanisms for Greenhouse Gas Emissions Reduction in the Mexican Power Sector. Energy Policy, 122, 287-299.

Becker, S., Rodriguez, R., Andresen, G., Schramm, S., \& Greiner, M. (2015). Transmission grid extensions during the build-up of a fully renewable pan-European electricity supply. Energy, 404-418.

Bistline, J. E., \& Weyant, J. P. (2013). Electric sector investments under technological and policyrelated uncertainties: a stochastic programming approach. Climatic Change, 121(2), 143-160.

Bohringer, C. (1998). The synthesis of bottom-up and top-down in energy policy modeling. Energy Economics, 20(3), 233-248.

Borgonovo, E., \& Plischke, E. (2016). Sensitivity analysis: A review of recent advances. European Journal of Operational Research, 248(3), 869-887. https://doi.org/10.1016/j.ejor.2015.06.032

Bosetti, V., Marangoni, G., Borgonovo, E., Anadon, L. D., Barron, R., McJeon, H. C., . . Friley, P. (2015). Sensitivity to Energy Technology Costs: A Multi-Model Comparison Analysis. Energy Policy, 80, 244-263.

Bramstoft, R., Pizarro-Alonso, A., Karlsson, K., Kofoed-Wiuff, A., \& Münster, M. (2018). STREAM - an energy scenario modelling tool. Energy Strategy Reviews, 21, 62-70.

Branger, F., Giraudeta, L.-G., Guivarcha, C., \& Quirion, P. (2015). Global sensitivity analysis of an energy-economy model of the residential building sector. Environmental Modelling \& Software, 70, 45-54.

Campolongo, F., Cariboni, J., \& Saltelli, A. (2007). An effective screening design for sensitivity analysis of large models. Environmental Modelling \& Software, 22, 1509-1518. 
Campolongo, F., Cariboni, J., \& Saltelli, A. (2007). An effective screening design for sensitivity analysis of large models. Environmental Modelling \& Software, 22, 1509-1518.

Chen, F., Huang, G. H., Fan, Y. R., \& Chen, J. P. (2017). A copula-based fuzzy chance-constrained programming model and its application to electric power generation systems planning. Applied Energy, 187, 291-309. https://doi.org/10.1016/j.apenergy.2016.11.065

Creutzig, F., Agoston, P., Goldschmidt, J. C., Luderer, G., Nemet, G., \& Pietzcker, R. C. (2017). The underestimated potential of solar energy to mitigate climate change. Nature Energy, 2(9), 1-9.

Danish Energy Agency. (2014). Energy scenarios for 2020, 2035 and 2050. Retrieved from http://www.ens.dk/sites/ens.dk/files/undergrund-forsyning/el-naturgasvarmeforsyning/Energianalyser/nyeste/energiscenarier_-_analyse_2014_web.pdf

Danish Ministry of Energy, Climate and Building. (2018). Energy Agreement. Retrieved February 3, 2019, from https://en.efkm.dk/media/12307/energy-agreement-2018.pdf

Danish Ministry of Energy, Utilities and Climate. (2018). Together for a greener future. Climate and Air proposal.

Dansk Energi. (2018). Electricity Price Outlook 2018: Perspectives for the power price in North West Europe towards 2035. Retrieved February 25, 2019, from https://www.danskenergi.dk/sites/danskenergi.dk/files/media/dokumenter/201806/Electricity_Price_Outlook_2018.pdf

EA Energy Analyses; Energinet. (2014). EAPP Regional Power System Master Plan.

Fais, B., Keppo, I., Zeyringer, M., Usher, W., \& Daly, H. (2016). Impact of technology uncertainty on future low-carbon pathways in the UK. Energy Strategy Reviews, 13-14, 154-168.

Fortes, P., Alvarenga, A., Seixas, J., \& Rodrigues, S. (2015). Long-term energy scenarios: Bridging the gap between socioeconomic storylines and energy modeling. Technological Forecasting and Social Change, 91, 161-178.

Fragkos, P., Kouvaritakis, N., \& Capros, P. (2015). Incorporating Uncertainty into World Energy Modelling: the PROMETHEUS Model. Environmental Modeling \& Assessment, 20(5), 549569.

Gargiulo, M., \& Gallachoir, B. O. (2013). Long-term energy models: Principles, characteristics, focus, and limitations. Wiley Interdisciplinary Reviews-Energy and Environment, 2(2), 158177.

Hall, L. M., \& Buckley, A. R. (2016). A review of energy systems models in the UK: Prevalent usage and categorisation. Applied Energy, 169, 607-628.

Hedenus, F., Johansson, D., \& Lindgren, K. (2013). A Critical Assessment of Energy-economyclimate Models for Policy Analysis. Journal of Applied Economics and Business Research, $3(2), 118-132$.

Helton, J. C., Johnson, J. D., Sallaberry, C. J., \& Storlie, C. B. (2006). Survey of sampling-based methods for uncertainty and sensitivity analysis. Reliability Engineering and System Safety, 91(10-11), 1175-1209.

Helton, J., \& Davis, F. (2003). Latin hypercube sampling and the propagation of uncertainty in analyses of complex systems. Reliability Engineering and System Safety, 81(1), 23-69. 
Hourcade, J.-C., Jaccard, M., Bataille, C., \& Ghersi, F. (2006). Hybrid modeling: New answers to old challenges - Introduction to the special issue of The Energy Journal. Energy Journal, 1, 1-11.

IEA. (2013). Nordic Energy Technology Perspectives: Pathways to a Carbon Neutral Energy Future. Retrieved from https://www.iea.org/publications/freepublications/publication/NETP.pdf

Ioannou, A., Angus, A., \& Brennan, F. (2017). Risk-based methods for sustainable energy system planning: A review. Renewable and Sustainable Energy Reviews, 74, 602-615.

IPCC, 2014: Climate Change 2014: Mitigation of Climate Change. Contribution of Working Group III to the Fifth Assessment Report of the Intergovernmental Panel on Climate Change [Edenhofer, O., R. Pichs-Madruga, Y. Sokona, E. Farahani, S. Kadner, K. Seyboth, A. Adler, I. Baum, S. Brunner, P. Eickemeier, B. Kriemann, J. Savolainen, S. Schlömer, C. von Stechow, T. Zwickel and J.C. Minx (eds.)]. Cambridge University Press, Cambridge, United Kingdom and New York, NY, USA.

Jouvenel, B. d. (1967). The art of conjecture. Basic Books.

Karlsson, K., \& Meibom, P. (2008). Optimal investment paths for future renewable based energy systems - Using the optimisation model Balmorel. International Journal of Hydrogen Energy, 33(7), 1777-1787.

Keppo, I., \& Strubegger, M. (2010). Short term decisions for long term problems - The effect of foresight on model-based energy systems analysis. Energy, 35, 2033-2042.

Kristensen, M. H., \& Petersen, S. (2016). Choosing the appropriate sensitivity analysis method for building energy model-based investigations. Energy and Buildings, 130, 166-176.

Kurowicka, D., \& Cooke, R. (2006). Uncertainty Analysis with High Dimensional Dependence Modelling. John Wiley \& Sons, Ltd.

Lempert, R. J., Popper, S. W., \& Bankes, S. C. (2003). Shaping the next one hundred years: New Methods for Quantitative, Long-Term Policy Analysis. Hentet 13. April 2018 fra https://www.rand.org/content/dam/rand/pubs/monograph_reports/2007/MR1626.pdf

Lunz, B., Stoecker, P., Eckstein, S., Nebel, A., Samadi, S., Erlach, B., . . Elsner, P. (2016). Scenariobased comparative assessment of potential future electricity systems - A new methodological approach using Germany in 2050 as an example. Applied Energy, 171, 555-580.

Mahony, T. (2014). Integrated scenarios for energy: A methodology for the short term. Futures, 55, 41-57.

Marcucci, A., Panos, E., Kypreos, S., \& Fragkos, P. (2019). Probabilistic assessment of realizing the $1.5{ }^{\circ} \mathrm{C}$ climate target. Applied Energy, 239, 239-251.

Mirakyan, A., \& De Guio, R. (2015). Modelling and uncertainties in integrated energy planning. Renewable and Sustainable Energy Reviews, 46, 62-69. https://doi.org/10.1016/j.rser.2015.02.028

Moradi, M. H., Hajinazari, M., Jamasb, S., \& Paripour, M. (2013). An energy management system (EMS) strategy for combined heat and power (CHP) systems based on a hybrid optimization method employing fuzzy programming. Energy, 49(1), 86-101.

Moret, S., Codina Gironés, V., Bierlaire, M., \& Maréchal, F. (2017). Characterization of input uncertainties in strategic energy planning models. Applied Energy, 202, 597-617. https://doi.org/10.1016/j.apenergy.2017.05.106. 
Morris, M. D. (1991). Factorial sampling plans for preliminary computational experiments. Technometrics, 33(2), 161-174.

Muela, E., Schweickardt, G., \& Garces, F. (2007). Fuzzy possibilistic model for medium-term power generation planning with environmental criteria. Energy Policy, 35(11), 5643-5655.

Nie, S., Huang, Z. C., Huang, G. H., Yu, L., \& Liu, J. (2018). Optimization of electric power systems with cost minimization and environmental-impact mitigation under multiple uncertainties. Applied Energy, 221, 249-267. https://doi.org/10.1016/j.apenergy.2018.03.194

Norden; IEA. (2016). Nordic Energy Technology Perspectives 2016: Cities, flexibility and pathways to carbon-neutrality. Retrieved from http://www.nordicenergy.org/wpcontent/uploads/2016/05/Nordic-Energy-Technology-Perspectives-2016.pdf

Nordhaus, W., \& Yohe, G. (1983). Future paths of energy and carbon dioxide emissions, Changing Climate: Report of the Carbon Dioxide Assessment Committee. Washington DC, USA: National Research Council, National Academy Press.

Onkal, D., Sayim, K. Z., \& Gonul, M. S. (2013). Scenarios as channels of forecast advice. Technological Forecasting and Social Change, 80(4), 772-788.

Pfenninger, S., \& Staffell, I. (2016). Long-term patterns of European PV output using 30 years of validated hourly reanalysis and satellite data. Energy, 114, 1251-1265.

Pfenninger, S., Hawkes, A., \& Keirstead, J. (2014). Energy systems modeling for twenty-first century energy challenges. Renewable and Sustainable Energy Reviews, 33, 74-86.

Pietzcker, R. C., Ueckerdt, F., Carrara, S., de Boer, H. S., Després, J., Fujimori, S., . . Luderer, G. (2017). System integration of wind and solar power in integrated assessment models: A crossmodel evaluation of new approaches. Energy Economics, 64, 583-599.

Pizarro Alonso, A. R., Cimpan, C., \& Münster, M. (2018). The climate footprint of imports of combustible waste in systems with high shares of district heating and variable renewable energy. Waste Management, 79, 800-814.

Pizarro-Alonso, A. R., Cimpan, C., Söderman, M. L., Ravn, H. V., \& Münster, M. (2018). The economic value of imports of combustible waste in systems with high shares of district heating and variable renewable energy. Waste Management, 79, 324-338.

Pye, S., Sabio, N., \& Strachan, N. (2015). An integrated systematic analysis of uncertainties in UK energy transition pathways. Energy Policy, 87, 673-684.

Ravn, H. (2001). The Balmorel Model: Theoretical Background. Retrieved March 2019, from http://balmorel.com/index.php/balmorel-documentation

Refsgaard, J. C., Sluijs, J. P., Brown, J., \& Keur, P. v. (2006). A framework for dealing with uncertainty due to model structure error. Advances in Water Resources, 26, 1586-1597.

Refsgaard, J. C., Sluijs, J. P., Højberg, A. L., \& Vanrolleghem, P. A. (2007). Uncertainty in the environmental modelling process e A framework and guidance. Environmental Modelling \& Software, 22, 1543-1556.

Renewables Ninja. (2019). Retrieved March 23, 2019, from https://www.renewables.ninja/

Rogelj, J., Shindell, D., Jiang, K., Fifita, S., Forster, P., Ginzburg, V., . . M.V. Vilariño. (2018). Mitigation Pathways Compatible with $1.5^{\circ} \mathrm{C}$ in the Context of Sustainable Development. In: 
Global Warming of $1.5^{\circ} \mathrm{C}$. An IPCC Special Report on the impacts of global warming of $1.5^{\circ} \mathrm{C}$ above pre-industrial levels and related global greenhouse gas emission pathways.

Rothenberg, J. (1989). The Nature of Modeling. Artificial Intelligence, Simulation and Modeling, 7592.

Saltelli, A., \& Annoni, P. (2010). How to avoid a perfunctory sensitivity analysis. Environmental Modelling \& Software, 25, 1508-1517.

Saltelli, A., Aleksankina, K., Becker, W., Fennell, P., Ferretti, F., Holst, N., . . Wu, Q. (2019). Why so many published sensitivity analyses are false: A systematic review of sensitivity analysis practices. Environmental Modelling and Software, 114, 29-39.

Saltelli, A., Ratto, M., Andres, T., Campolongo, F., Cariboni, J., Gatelli, D., . . Tarantola, S. (2008). Global Sensitivity Analysis. The Primer. John Wiley and Sons. doi:10.1002/9780470725184

Saltelli, A., Tarantola, S., Campolongo, F., \& Ratto, M. (2004). Sensitivity Analysis in Practice: A Guide to Assessing Scientific Models. John Wiley \& Sons, Ltd.

Scholz, Y., Gils, H. C., \& Pietzcker, R. C. (2017). Application of a High-Detail Energy System Model to Derive Power Sector Characteristics at High Wind and Solar Shares. Energy Economics, $64,568-582$.

Sin, G., Gernaey, K. V., \& Lantz, A. E. (2009). Good modeling practice for PAT applications: Propagation of input uncertainty and sensitivity analysis. Biotechnology Progress, 25(4), 1043-1053.

Solano-Rodríguez, B., Alonso, A. R., Vaillancourt, K., \& Martin-del-Campo., C. (2018). Mexico's Transition to a Net-Zero Emissions Energy System: Near Term Implications of Long-Term Stringent Climate Targets. In Lecture Notes in Energy 64 (pp. 315-331).

Soroudi, A., \& Amraee, T. (2013). Decision making under uncertainty in energy systems: State of the art. Renewable and Sustainable Energy Reviews, 28, 376-384.

Sterman, J. D. (2002). All models are wrong: reflections on becoming a systems scientist. System Dynamics Review, 18(4), 501-531.

Stirling, A. (2010). Keep it complex. Nature, 468, 1029-1031.

Sun, N., Ellersdorfer, I., \& Swider, D. J. (2008). Model-Based Long-Term Electricity Generation System Planning under Uncertainty. DRPT 2008, 1298-1304.

Trutnevyte, E. G., \& Strachan, N. (2016). Reinvigorating the scenario technique to expand uncertainty consideration. Climatic Change, 135(3-4), 373-379.

Tveten, Å. G. (2015). PhD Thesis - Renewable energy in Northern European power markets: effects, challenges and integration options.

UK Department for Business, Energy \& Industrial Strategy. (2017). Contracts for Difference Second Allocation Round Results. Retrieved March 2, 2019, from https://assets.publishing.service.gov.uk/government/uploads/system/uploads/attachment_data/ file/643560/CFD_allocation_round_2_outcome_FINAL.pdf

Usher, W. (2015). The Value of Global Sensitivity Analysis for Energy System Modelling. Conference: International Energy Workshop at Abu Dhabi.

Usher, W., \& Strachan, N. (2012). Critical mid-term uncertainties in long-term decarbonisation pathways. Energy Policy, 41, 433-444. 
van Asselt, M. B., \& Rotmans, J. (2002). Uncertainty in integrated assessment modelling - From positivism to pluralism. Climatic Change, 54(1-2), 75-105.

van't Klooster, S. A., \& van Asselt, B. A. (2006). Practising the scenario-axes technique. Future, 1, $15-30$.

Venturini, G., Pizarro-Alonso, A., \& Münster, M. (2019). How to maximize the value of residual biomass resources: The case of straw in Denmark. Applied Energy, 250, 369-388.

Walker, W., Harremoës, P., Rotmans, J., Sluijs, J. V., M.B.A. Van Asselt, P. J., \& Krauss, M. K. (2003). Defining Uncertainty - A Conceptual Basis for Uncertainty Management in ModelBased Decision Support. Integrated Assessment, 4(1), 5-17.

Wiese, F., Bökenkamp, G., Wingenbach, C., \& Hohmeyer, O. (2014). An open source energy system simulation model as an instrument for public participation in the development of strategies for a sustainable future. Wiley Interdisciplinary Reviews: Energy and Environment, 3(5), 490504.

Wiese, F., Bramstoft, R., Koduvere, H., Alonso, A. R., Balyk, O., Kirkerud, J. G., . . Ravn., H. V. (2018). Balmorel Open Source Energy System Model. Energy Strategy Reviews, 20, 26-34.

Wilk, J. (1991). The art of the long view: Planning for the future in an uncertain world. Long Range Planning, 24(6), 110-114.

Xiong, W., Zhang, D., Mischke, P., \& Zhang, X. (2014). Impacts of Renewable Energy Quota System on China's Future Power Sector. Energy Procedia, 61, 1187-1190.

Yu, L., Li, Y. P., Huang, G. H., Fan, Y. R., \& Nie, S. (2018). A copula-based flexible-stochastic programming method for planning regional energy system under multiple uncertainties: A case study of the urban agglomeration of Beijing and Tianjin. Applied Energy, 210, 60-74. https://doi.org/10.1016/j.apenergy.2017.10.099

Yue, X., Pye, S., DeCarolis, J., Li, F. G., Rogan, F., \& Gallachoir, B. O. (2018). A review of approaches to uncertainty assessment in energy system. Energy Strategy Reviews, 21, 204217.

Zeng, Y., Cai, t., Huang, G., \& Dai, J. (2011). A Review on Optimization Modeling of Energy Systems Planning and GHG Emissions Mitigation under Uncertainty. Energies, 4, 1624-1656.

Zhu, Y., Huang, G. H., He, L., \& Zhang, L. Z. (2012). An interval full-infinite programming approach for energy systems planning under multiple uncertainties. International Journal of Electrical Power and Energy Systems, 43(1), 375-383. 